\title{
SANDRA ALIBERTI
}

Influência da síndrome da dor patelofemural no alinhamento postural dos membros inferiores e na distribuição da pressão plantar durante a marcha e descer escadas

Dissertação apresentada à Faculdade de Medicina da Universidade de São Paulo para obtenção do título de Mestre em Ciências

Área de concentração: Movimento, Postura e Ação Humana

Orientadora: Profa. Dra. Isabel de Camargo Neves Sacco

São Paulo 


\section{SANDRA ALIBERTI}

Influência da síndrome da dor patelofemural no alinhamento postural dos membros inferiores e na distribuição da pressão plantar durante a marcha e descer escadas

Dissertação apresentada à Faculdade de Medicina da Universidade de São Paulo para obtenção do título de Mestre em Ciências

Área de concentração: Movimento, Postura e Ação Humana

Orientadora: Profa. Dra. Isabel de Camargo Neves Sacco

São Paulo 
Dedico ao meu marido Nê e ao meu filho Edu 


\section{AGRADECIMENTOS}

Ao meu marido Nê pelo amor, constante incentivo e incrível paciência necessária ao companheiro de jornada de mestrado e de vida.

Ao meu filho Eduardo, que neste momento, com oitos anos define Mestrado como algo que não termina nunca. Sei que pareceram intermináveis as horas em que estive ausente, ocupada e pré-ocupada durante estes anos. Mestrado termina!

Aos meus pais Alberto (em sua memória, estou certa de que você ficaria muito feliz) e Lucy pela valorização do conhecimento e por sempre acreditarem em mim.

Aos meus tios Zé e Tia Paula por constantemente me apoiarem, torcerem, acreditando nas minhas idéias e possibilidades.

Aos meus irmãos Adalberto, Aldo, Adriano e Gisela. Foram muitos momentos de ausência de nosso convívio.

Às grandes amigas Miriam e Simone pela torcida, ajuda inestimável com a amostra controle e por compartilharem comigo esta paixão pelo movimento.

Às amigas Cissa e Eliane pelo companheirismo que me trouxe tranquilidade para eu poder me dedicar!

À minha orientadora Isabel por me introduzir com mestria nos caminhos do conhecimento científico, apoiando e incentivando minhas perguntas e inquietações e dando suporte aos momentos difíceis que enfrentei. Você me ensinou o significado de "fazer acontecer"!

À Mariana pela inestimável ajuda nas coletas de dados, com um senso de responsabilidade raro na sua idade! 
Aos companheiros de laboratório Carla, Paulinha, Tatiana, Vitor, Aline Arcanjo, Naomi, Bergson, Francis, Ana Paula, Andreja, Denise Pripas, Denise Lacase, Aline Kimura, Adriana, Mitie que contribuíram muito na minha trajetória dentro do Laboratório, no processo e resultado final deste trabalho. Sinto-me privilegiada em conviver com pessoas tão competentes e agradáveis!

Aos professores Dr. Fábio Serrão, Dra. Amélia Pasqual e Dra. Clarice Tanaka pelas preciosas contribuições feitas na fase de qualificação deste trabalho.

Ao Rogério pela fundamental ajuda com a linguagem Matlab na análise dos dados.

Ao Dr. Arnone e à Anice pelo encaminhamento da amostra de pacientes, sem a qual este estudo não seria viável.

A todas as pessoas que voluntariamente participaram como sujeitos das coletas de dados.

À FAPESP pela bolsa concedida possibilitando minha dedicação integral a este trabalho. 
O todo sem a parte não é todo, A parte sem o todo não é parte, Mas se a parte o faz todo, sendo parte, Não se diga que é parte, sendo todo.

Em todo o Sacramento está Deus todo E todo assiste inteiro em qualquer parte, E feito em partes todo em toda a parte, Em qualquer parte sempre fica todo.

Gregório de Matos 


\section{NORMALIZAÇÃO ADOTADA}

Esta dissertação está de acordo com as seguintes normas, em vigor no momento desta publicação:

Referências: adaptado de International Committee of Medical Journals Editors (Vancouver)

Universidade de São Paulo. Faculdade de Medicina. Serviço de Biblioteca e Documentação. Guia de apresentação de dissertações, teses e monografias. Elaborado por Anneliese Carneiro da Cunha, Maria Julia de A. L. Freddi, Maria F. Crestana, Marinalva de Souza Aragão, Suely Campos Cardoso, Valéria Vilhena. 2a . Ed. São Paulo: Serviço de Biblioteca e Documentação; 2005.

Abreviaturas dos títulos dos periódicos de acordo com List of Journals Indexed in Index Medicus. 


\section{SUMÁRIO}

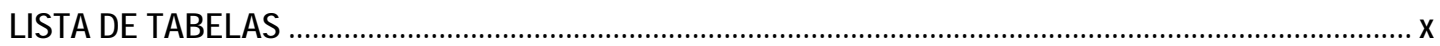

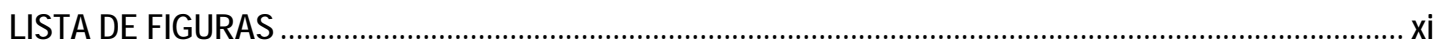

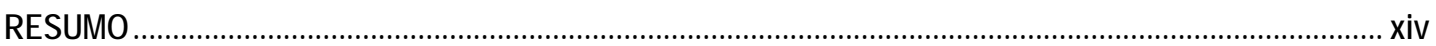

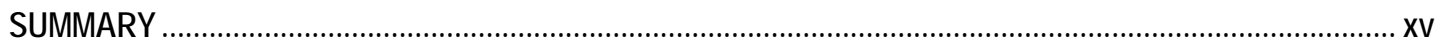

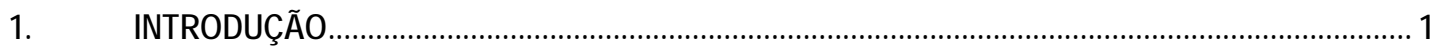

2. OBJETIVOS

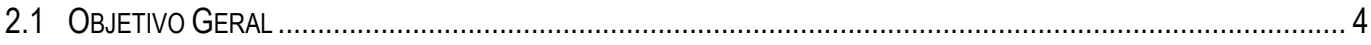

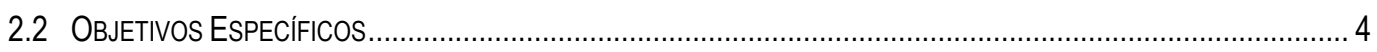

3. ATUALIZAÇÃO DA LITERATURA

3.1 EPIDEMIologia, CARACTERIZAÇão e FATORES de RISCO PARA A SíndRome da Dor PATELOFEMURAL ........... 6

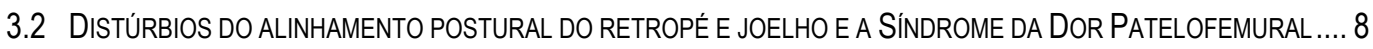

3.3 DISTÚRBIOS NO ALINHAMENTO DINÂMICO DOS MEMBROS INFERIORES E SíndROME DA DOR PATELOFEMURAL 12

3.4 DISTRIBUIÇÃo DA PRESSÃo PLANTAR E A SÍNDROME DA DoR PATELOFEMURAL ...................................... 18

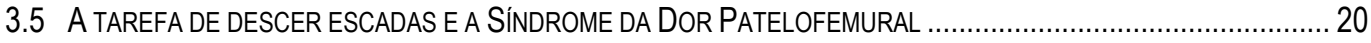

4. MÉTODOS

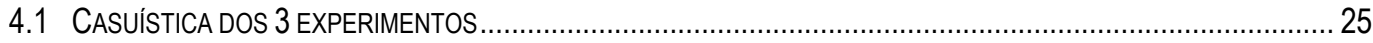

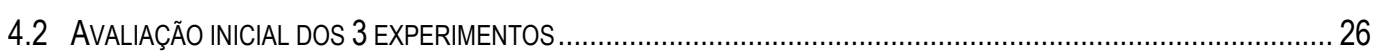

$5 \quad$ EXPERIMENTO 1

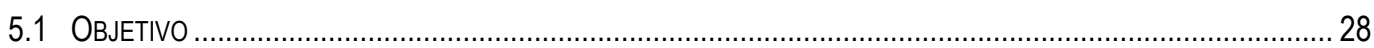

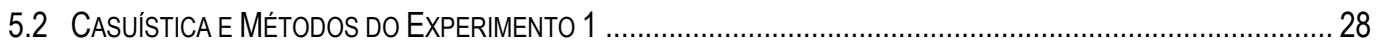

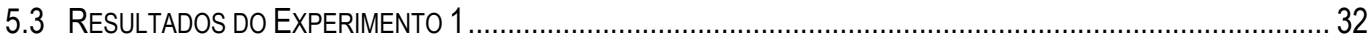

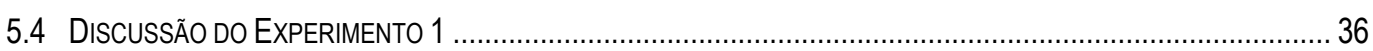

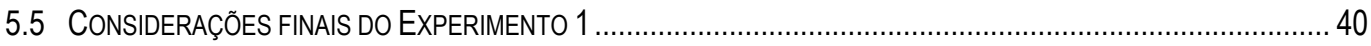

$6 \quad$ EXPERIMENTO 2

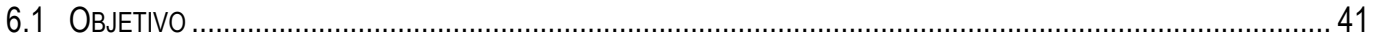

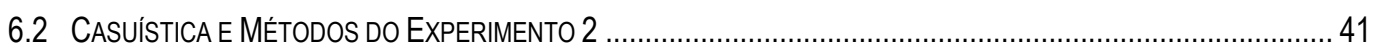

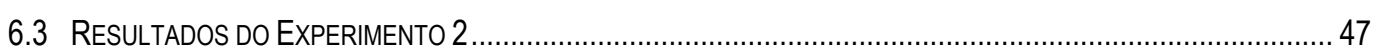

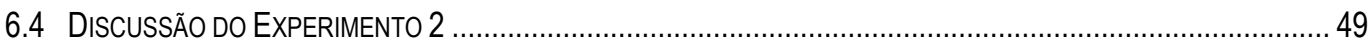

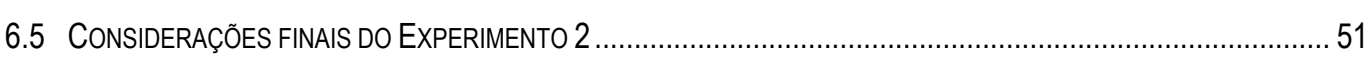


$7 \quad$ EXPERIMENTO 3

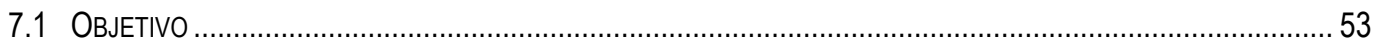

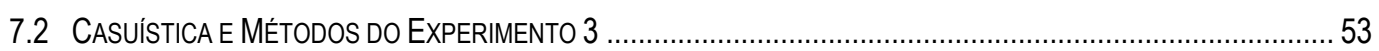

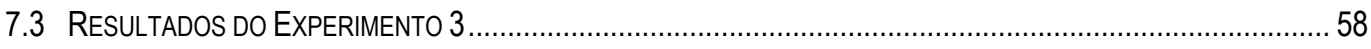

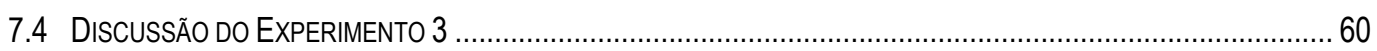

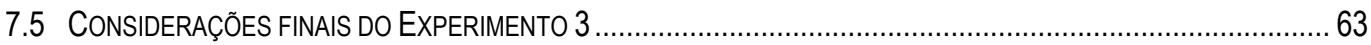

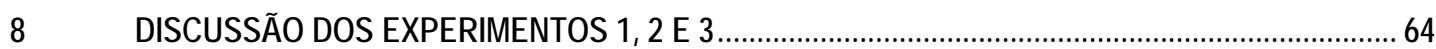

$9 \quad$ CONCLUSÕES

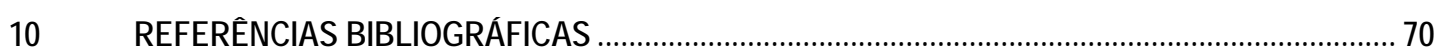

ANEXO 1 - TERMO DE CONSENTIMENTO LIVRE E ESCLARECIDO

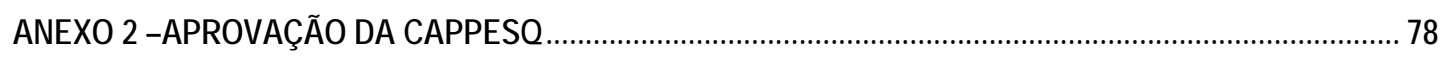

ANEXO 3 - ESCALA FUNCIONAL DO JOELHO DE LYSHOLM ................................................................ 79

ANEXO 4 - RESUMO XI EMED SCIENTIFIC MEETING DUNDEE, ESCÓCIA, 2008 ........................................ 80

ANEXO 5 - RESUMO XI EMED SCIENTIFIC MEETING DUNDEE, ESCÓCIA, 2008 ..................................... 82 


\section{LISTA DE TABELAS}

Tabela 1. Médias, desvios padrão e valores do $p$ do ângulo do retropé ,ângulo $Q$ e medida da orientação médio-lateral da patela dos grupos com síndrome da dor patelofemural(GSPF) e controle (GC) ............................................. 33

Tabela 2. Médias, desvios padrão e valores do $p$ do teste post hoc da àrea de contato $\left(\mathrm{cm}^{2}\right)$ nas 6 áreas plantares do grupo controle (GC) e grupo síndrome da dor patelofemural (GSPF) durante o descer escadas.

Tabela 3. Médias e desvios padrão da integral da pressão (kPa.s) nas 6 áreas plantares do grupo controle (GC) e grupo síndrome da dor patelofemural (GSPF) durante 0 descer escadas.

Tabela 4. Médias, desvios padrão e valores do $p$ do post hoc de newman-keuls da área de contato $\left(\mathrm{cm}^{2}\right)$ e pico de pressão $(\mathrm{kPa})$ nas 6 áreas plantares durante 0 contato inicial, médio-apoio e propulsão do apoio da marcha entre os grupos controle (GC) e síndrome da dor patelofemural (GSPF)....... 59 


\section{LISTA DE FIGURAS}

Figura 1. Representação do ângulo do quadríceps (acima = vetor do tendão do quadríceps, abaixo $=$ vetor do ligamento patelar, horizontal $=$ vetor lateral resultante $d a$ contração do músculo quadríceps) (Adaptado de Powers, 2003). 9

Figura 2. Medida da orientação médio-lateral da patela (Adaptado de Herrington,2002)..... 11

Figura 3. Esquema da cascata patofisiológica onde a pronação excessiva pode levar à rotação medial dos membros inferiores e aumento do valgo fisiológico do joelho ( Adaptado de Powers, 2003). 15

Figura 4. Vetores de força da articulação patelofemural (acima = vetor do tendão do quadríceps, abaixo = vetor do ligamento patelar, horizontal $=$ vetor resultante responsável pela compressão da patela no fêmur) (Adaptado de La Botz, 2004)

Figura 5. Fluxograma do protocolo de avaliação dos 3 experimentos. 24

Figura 6. Representação do cálculo do ângulo $Q$ por fotogrametria...... 30

Figura 7. Representação do cálculo do ângulo do retropé por fotogrametria. 30

Figura 8. Distribuição das porcentagens de ângulos do retropé varos, valgos e valgos aumentado no grupo controle (GC) e no grupo síndrome da dor patelofemural (GSPF). 34

Figura 9. Distribuição das porcentagens de ângulos $Q$ diminuídos, normais e aumentados no grupo controle (GC) e no grupo síndrome da dor patelofemural (GSPF). 35 
Figura 10. Distribuição das porcentagens de patelas medializadas, centralizadas e lateralizadas no grupo controle (GC) e no grupo síndrome da dor patelofemural (GSPF). 36

Figura 11. Pedar X System, bateria, condicionador (box) com cabos para conexão nas palmilhas, fitas para fixação do equipamento no sujeito e dispositivo bluetooth.Situação exemplar do sujeito com as palmilhas colocadas dentro de meias antiderrapantes, usando a mochila nas costas contendo o condicionador do Pedar X 43

Figura 12. Escada construída com dimensões conforme as normas da ABNT. 44

Figura 13. Representação da divisão da superfície plantar em 6 áreas para a análise da distribuição da pressão plantar : retropé medial (RM), retropé central $(R C)$,retropé lateral $(R L)$, médio-pé $(M P)$, antepé medial $(A M)$ e antepé lateral (AM) 46

Figura 14. Médias e desvios padrão do pico de pressão (kPa) nas 6 áreas plantares do grupo controle (GC) e grupo síndrome da dor patelofemural (GSPF) durante 0 descer escadas. 48

Figura 15. Eletrogoniômetro biaxial de tornozelo (1= bloco móvel, 2 = bloco fixo). 54

Figura 16. Esquema da sincronização entre os dados de distribuição da pressão plantar (Pedar X System) e variação angular de flexão e extensão do tornozelo (eletrogoniômetro) por meio do box sincronizador do pedar (sinal TTL). 55

Figura 17. Representação da divisão das fases do apoio da marcha a partir da variação angular do tornozelo, sendo flexão (valores positivos) e extensão (valores negativos). $O$ contato inicial está entre $A-B, 0$ médio-apoio entre $B-C$ e a propulsão entre C-D 57 
Figura 18. Integral da pressão (kPa.s) nas 6 áreas plantares durante o contato Inicial, 0 médio-apoio e a propulsão da fase de apoio da marcha entre os grupos controle (GC) e síndrome da dor patelofemural (GSPF). RM = retropé medial, $\mathrm{RC}=$ retropé central, $R L=$ retropé lateral, $M=$ médio-pé, $A M=$ antepé medial e $A M=$ antepé lateral. 60 


\section{RESUMO}

Aliberti, S. Influência da síndrome da dor patelofemural no alinhamento postural dos membros inferiores e na distribuição da pressão plantar durante a marcha e descer escadas [dissertação]. São Paulo: Faculdade de Medicina, Universidade de São Paulo; 2008. 83 p.

A síndrome da dor patelofemural é uma das disfunções mais comuns que acometem o joelho, principalmente mulheres jovens fisicamente ativas. No entanto, o tratamento permanece desafiador por carecer de bases científicas que direcionem sua reabilitação. Distúrbios no alinhamento estático e dinâmico dos membros inferiores, como a pronação excessiva do retropé, têm sido associados na clínica e embasados teoricamente como fatores de risco para a disfunção. No entanto, estudos experimentais que embasem esta relação ainda são controversos. O objetivo geral deste estudo foi verificar a influência da síndrome da dor patelofemural no alinhamento postural do retropé e joelho, assim como na distribuição da pressão plantar durante a fase apoio do descer escadas e em três subfases do apoio da marcha. Foram estudados 77 adultos jovens de ambos os sexos, divididos em grupo controle $(G C=47)$ e grupo síndrome da dor patelofemural (GSPF=30). Para responder a questões científicas específicas, foram realizados três experimentos. 0 experimento 1 teve o objetivo específico de verificar a associação entre a síndrome da dor patelofemural e 0 alinhamento postural dos membros inferiores $(n=77 ; G C=47, G S P F=30)$. Para tanto, foram avaliadas três medidas clínicas: o ângulo do retropé, o ângulo $Q$ (fotogrametria digital) e a orientação médiolateral da patela (método adaptado de Mc Connell). 0 experimento 2 teve como objetivo específico investigar a distribuição da pressão plantar de indivíduos com e sem diagnóstico de síndrome da dor patelofemural durante o descer escadas, e avaliar a dor dos sujeitos com essa disfunção antes e após a tarefa proposta ( $n=74 ; G C=44, G S P F=30)$. Para tanto, avaliouse a distribuição da pressão plantar por meio de palmilhas capacitivas (Pedar X System) na fase de apoio do descer escadas e a dor referida pelos sujeitos pela escala analógica visual de dor antes e depois da tarefa motora. 0 experimento $3(n=57 ; G C=35, G S P F=22)$ buscou especificamente avaliar a influência da síndrome da dor patelofemural na distribuição da pressão plantar durante o contato inicial, médio-apoio e propulsão da fase de apoio da marcha. Os principais resultados demonstraram que não houve influência da disfunção no alinhamento postural do retropé e joelho. No entanto, durante o descer escadas, a síndrome da dor patelofemural esteve associada à um contato medialmente direcionado no retropé e médio-pé, assim como menores sobrecargas plantares, provavelmente associadas ao aumento significativo da dor relatada pelos sujeitos após a tarefa. Na marcha, os sujeitos com a disfunção realizaram novamente um contato inicial medialmente direcionado no retropé e uma propulsão mais lateralizada no antepé. Os resultados deste estudo mostram que a síndrome da dor patelofemural não esteve relacionada ao alinhamento postural do retropé e joelho, mas influenciou o padrão dinâmico da distribuição da pressão plantar tanto na marcha como no descer escadas. Estes achados confirmam a importância da avaliação dinâmica durante a reabilitação dos indivíduos com esta disfunção.

Descritores: Síndrome da dor patelofemural, biomecânica, extremidade inferior, pronação, postura, marcha. 


\section{SUMMARY}

Aliberti, A. Influence of patellofemoral pain syndrome on lower extremity postural alignment and plantar pressure distribution during stair descent and gait [dissertation]. São Paulo: Faculdade de Medicina, Universidade de São Paulo; 2008. 83 p.

Patellofemoral pain syndrome is one of the most common dysfunctions of the knee, particularly among young physically active females. Its treatment remains challenger due to the lack of scientific rationales bases to guide its rehabilitation. Static and dynamic misalignment of the lower extremity, like excessive rearfoot pronation has been clinically and theoretically associated as risk factors for this dysfunction. However, scientific studies to confirm this association are still controversial. The general purpose of this study was to verify the influence of patellofemoral pain syndrome on rearfoot and knee postural alignment as well as on plantar pressure distribution during the stance phase of stair descent and three sub phases of stance gait. 77 young adults of both sexes divided in to control group (GC=47) and patellofemoral pain goup(PFPG $=30$ ) were studied. Three experiments were realized in order to respond the specific scientific questions. The experiment 1 had the specific purpose of verify the association between patellofemoral pain syndrome and postural alignment of rearfoot and knee $(n=77 ; C G=47, P F P G=30)$. Therefore, three clinical measurements were evaluated: rearfoot angle, $Q$ angle (digital photogrammetry) and the medio-lateral orientation of the patella (adapted from McConnell). The experiment 2 aimed specifically to investigate plantar pressure distribution in subjects with and without patellofemoral pain syndrome, during the stair descent, and evaluate the pain referred by the subjects before and after the motor task $(n=74 ; C G=44, P F P G=30)$, plantar pressure distribution was evaluated with capacitive insoles(Pedar X System) during the stance phase of stair descent as well as the pain referred by the subjects by Visual Analogue Scale before and after the task. The experiment 3 intended specifically to verify the influence of patellofemoral pain syndrome on plantar pressure distribution during initial contact, midstance and propulsion of the gait stance $(n=57$; $\mathrm{GC}=35, \mathrm{GSPF}=22$ ). The principal results of this study showed that there was no influence of the dysfunction on postural alignment of rearfoot and knee. However, patellofemoral pain syndrome during the stair descent was related to a medially directed contact at the rearfoot and midfoot and lower plantar loads probably due to the increase in pain observed after the task. During gait, the subjects with the dysfunction showed again an initial contact medially directed at the rearfoot and laterally directed propulsion on forefoot. The results of this study show that patellofemoral pain syndrome was not associated to postural alignment but influenced the plantar pressure distribution during gait as well as stair descending task. These findings confirm the importance of the dynamic evaluation of subjects with this dysfunction during their rehabilitation.

Descriptors: Patellofemoral pain syndrome, biomechanics, lower extremity, pronation, posture, gait. 


\section{INTRODUÇÃO}

A Síndrome da Dor Patelofemoral (SPF) é uma das queixas musculoesqueléticas mais comuns da articulação do joelho entre mulheres jovens fisicamente ativas, chegando a acometer 25-36\% da população em geral (DeHaven e Lintner, 1986; Tauton et al., 2002; 2004).

A reabilitação da SPF, torna-se desafiadora principalmente pela falta de consenso quanto à sua etiologia de origem multifatorial (La Botz, 2004; LaBella, 2004; Heintjes et al., 2005). Portanto, observa-se que o estudo dos fatores etiológicos relacionados à SPF torna-se relevante por tratar-se de uma afecção musculoesquelética bastante frequente que causa dor, diminuição da qualidade de vida, limitando ou mesmo impedindo a prática de atividade física de indivíduos que eram na sua maioria fisicamente ativos antes do aparecimento da disfunção.

A SPF tem sido relacionada a uma combinação de fatores de risco intrínsecos e extrínsecos(La Botz, 2004). Os fatores de risco extrínsecos mais relatados são aqueles associados ao equipamento e/ou características da atividade física ou esportiva realizada (Messier et al., 1991); enquanto que os fatores de risco intrínsecos tradicionalmente associados à SPF na literatura são as variações anatômicas da tróclea femoral, 0 desequilíbrio e/ou fraqueza muscular do quadríceps femoral, encurtamento dos músculos relacionados à cinesilogia da articulação do joelho - quadríceps femoral, isquiotibiais, ileotibial, gastrocnêmios - retesamento dos tecidos conjuntivos adjacentes à patela, assim como distúrbios no alinhamento estático e dinâmico dos membros inferiores (Powers, 2003; LaBella, 2004) 
A inclusão dos distúrbios no alinhamento postural estático e dinâmico dos membros inferiores como fatores de risco para a SPF, tem deslocado a discussão sobre a realização de uma reabilitação desta disfunção exclusivamente focada na articulação do joelho para uma abordagem que abrange a avaliação e intervenção das articulações dos membros inferiores como uma cadeia cinética (Powers, 2003).

O alinhamento postural do retropé está teoricamente relacionado ao ângulo $Q$ e à orientação médio-lateral da patela de maneira que um aumento do valgo do retropé estático estaria relacionado a uma excessiva e/ou prolongada pronação da subtalar no movimento. Esta pronação excessiva induziria a uma excessiva rotação medial da tíbia em cadeia cinética fechada. Esta rotação medial da tíbia induziria uma rotação medial do fêmur para manter a relativa rotação lateral do platô tibial em relação aos côndilos femorais associada com a extensão do joelho na fase de médio-apoio na marcha. 0 aumento da rotação medial do fêmur ampliaria o ângulo $Q$ e consequentemente o vetor de força que traciona a patela lateralmente no plano frontal. Essa resultante lateral aumentada poderia acrescer as forças de contato e a pressão na articulação patelofemural (Tibério 1987; Powers, 2003).

No entanto, apesar de difundida na clínica e teoricamente contemplada muitas ainda são as controvérsias e lacunas científicas no que tange a associação entre 0 alinhamento postural e dinâmico dos membros inferiores e a SPF (Fredericson e Yoon, 2006).

Earl e Hertel e Denegar (2005) encontraram um aumento da magnitude de pronação durante a tarefa de descida lateral de um degrau e Levinger e Gilleard (2007) uma pronação prolongada durante a marcha em sujeitos com SPF. Por outro lado, Messier et al. (1991) em um estudo durante a corrida e Powers et al. (2002) estudando a marcha não encontraram diferença na magnitude ou tempo de pronação do retropé entre sujeitos com e sem SPF. Uma recente revisão da literatura apontou a necessidade de mais evidências provenientes de 
estudos clínicos e biomecânicos para se justificar o uso de calçados que restringem a movimentação do complexo tornozelo-pé na reabilitação da SPF, tais como o movimento de pronação excessiva ou prolongada do retropé (Cheung et al., 2006).

Para tanto, acredita-se que estudos que avaliem o alinhamento postural do retropé e joelho por meio da fotogrametria digital, assim como a distribuição dinâmica da pressão plantar em diferentes tarefas de locomoção em sujeitos com SPF podem contribuir para o esclarecimento desta associação.

A pressão plantar tem sido utilizada como instrumento de avaliação funcional nas disfunções musculoesqueléticas dos membros inferiores. Willems et al. (2006) concluíram que os sujeitos que desenvolveram lesões por estresse nos membros inferiores relacionadas à corrida apresentavam alterações na distribuição da pressão plantar, como maiores pressões nas porções mediais do pé associadas à uma maior pronação do retropé em relação aos sujeitos que não desenvolveram lesões. Nesse sentido, a avaliação da distribuição da pressão plantar pode acrescentar bases racionais para a reabilitação da SPF, ajudando a elucidar o comportamento da interface do pé com o solo como um reflexo do comportamento do alinhamento dinâmico dos membros inferiores.

Esta discussão empírica visa em última análise melhorar a reabilitação de pacientes com SPF, pois os resultados obtidos podem ser utilizados como evidências para otimizar 0 programa de tratamento por meio dos exercícios utilizados, uso de calçados, taping e órteses adequados, melhorando a relação custo-benefício da abordagem terapêutica desta disfunção. 


\section{OBJETIVOS}

\subsection{Objetivo Geral}

O objetivo geral deste estudo foi verificar a influência da síndrome da dor patelofemural no alinhamento postural do retropé e joelho, assim como na distribuição da pressão plantar durante a fase apoio do descer escadas e em três subfases do apoio da marcha.

\section{$2.2 \quad$ Objetivos Específicos}

Para responder aos problemas científicos de naturezas distintas, este estudo foi conduzido em três experimentos, sendo o primeiro experimento referente ao estudo da influência da Síndrome da Dor Patelofemural no alinhamento postural do retropé e joelho; o segundo experimento, o estudo da influência da Síndrome da Dor Patelofemural na distribuição da pressão plantar durante a fase de apoio do descer escadas; e terceiro experimento, o estudo da influência da Síndrome da Dor Patelofemural na distribuição da pressão plantar durante as três subfases do apoio da marcha.

Desta forma, os objetivos específicos do presente estudo foram:

Experimento 1

- Verificar se existe associação entre o alinhamento postural do retropé, o ângulo Q, assim como a orientação médio-lateral da patela e a Síndrome da Dor Patelofemural. 
Experimento 2

- Investigar a distribuição da pressão plantar em indivíduos com e sem diagnóstico de Síndrome da Dor Patelofemural durante o descer escadas, e avaliar a dor dos sujeitos com essa disfunção antes e após a tarefa proposta.

\section{Experimento 3}

- Avaliar a influência da Síndrome da Dor Patelofemural na distribuição da pressão plantar durante o rolamento do pé na fase de apoio da marcha em três sub-fases: no contato inicial, médio-apoio e na propulsão. 


\section{ATUALIZAÇÃO DA LITERATURA}

Nesta atualização da literatura, serão descritos estudos que abordaram os seguintes tópicos: epidemiologia, caracterização e fatores de risco para a SPF, distúrbios do alinhamento postural dos membros inferiores e a SPF, pronação excessiva do retropé e a SPF, distribuição da pressão plantar e a SPF e a tarefa de descer escadas e a SPF.

As bases de dados PubMed, LILACS, EMBASE, Google Scholar, Scielo, Portal CAPES foram consultadas, abrangendo o período de 1985 a 2008, utilizando-se as palavraschaves: síndrome da dor patelofemural, biomecânica, pressão plantar, extremidade inferior, pronação, postura, marcha e seus correspondentes em inglês.

\subsection{Epidemiologia, caracterização e fatores de risco para a Síndrome da Dor Patelofemural}

A nomenclatura que envolve as disfunções da articulação patelofemural é confusa, levando muitas vezes ao desentendimento entre os profissionais de saúde e pacientes, no que diz respeito ao diagnóstico e tratamento das diversas alterações desta articulação (Grelsamer, 2005). O termo Síndrome da Dor Patelofemural foi escolhido para ser usado neste estudo por ser o descritor que se encontra atualmente nos Descritores em Ciência da Saúde (DeCS).

A Síndrome da Dor Patelofemural (SPF) é uma das queixas musculoesqueléticas mais comuns da articulação do joelho, afetando atletas e não atletas, chegando a acometer 25-36\% da população em geral. Sua incidência, no entanto, é maior entre adolescentes e 
adultos jovens fisicamente ativos do sexo feminino, atingindo $10 \%$ das atletas jovens do sexo feminino e 7\% dos atletas jovens do sexo masculino (LaBella, 2004). Segundo Tauton et al. (2002) em um estudo realizado pra avaliar a incidência de lesões em corredores, a SPF foi a disfunção mais frequente.

O diagnóstico diferencial da SPF deve sempre ser feito entre outras disfunções que atingem a articulação do joelho, principalmente na sua porção anterior. Entre estas estão a subluxação ou luxação patelar e a tendinite patelar. O termo SPF muitas vezes é usado como sinônimo de condromalácea patelar. É importante ressaltar que a condromalácea patelar trata-se de um achado cirúrgico de degeneração da cartilagem hialina patelar, portanto, não deve ser usado como diagnóstico clínico(Calmbach e Hutchens, 2003).

O sintoma mais frequentemente relatado na SPF é a dor difusa peripatelar ou retropatelar uni ou bilateral, exacerbada por atividades como descer ou subir escadas, agachar ou permanecer sentado com os joelhos fletidos por um longo período. Outros sinais e sintomas associados são crepitação durante a flexão / extensão do joelho e falseio. 0 derrame intra -articular é raro, entretanto, pode haver ocorrência de edema próximo ao ápice da patela (La Botz, 2004).

Como mencionado anteriormente, a SPF é uma disfunção de origem multifatorial, ou seja, provem de uma combinação de fatores de risco intrínsecos e extrínsecos (Juhn, 1999; La Botz, 2004). Os fatores de risco extrínsecos mais relatados são aqueles associados à realização de atividade física ou esportiva como a superfície, equipamento - tênis, ou ainda volume e intensidade da atividade física realizada (Messier et al., 1991).

Os fatores de risco intrínsecos comumente associados à SPF na literatura são: variações anatômicas da tróclea femoral, o desequilíbrio e/ou fraqueza muscular do quadríceps femoral, encurtamento dos músculos da extremidade inferior - quadríceps 
femoral, isquiotibiais, ileotibial, gastrocnêmios e sóleo - retesamento dos tecidos conjuntivos adjacentes à patela, assim como distúrbios no alinhamento postural e dinâmico dos membros inferiores (Powers, 2003; Fredericson e Yoon, 2006; Bevilaqua-Grossi, 2007).

\subsection{Distúrbios do alinhamento postural do retropé e joelho e a Síndrome da Dor Patelofemural}

Segundo Fredericson e Yoon (2006), não existe um teste ou medida clínica que seja considerado padrão ouro no diagnóstico da SPF, e sim algumas mensurações clínicas que em conjunto confirmam o diagnóstico desta disfunção. $O$ ângulo do retropé, o ângulo $Q$ assim como a medida da orientação médio-lateral da patela são exemplos de medidas clínicas freqüentemente empregadas na avaliação destes indivíduos dentro do processo de reabilitação da SPF(Livingston, 1998; Livingston e Mandigo, 2003; Herrington, 2008).

O alinhamento postural do retropé é usado na tomada de decisão sobre a necessidade ou não de se aplicar órteses ou taping anti-pronação como tratamento coadjuvante à cinesioterapia na clínica fisioterapeutica (Eng e Pierrynowski, 1993). A medida da orientação médio-lateral da patela, por sua vez, é utilizada na tomada de decisão quanto ao uso do taping patelar com o intuito de melhorar o alinhamento patela/fêmur durante os movimentos de flexão e extensão do joelho (McConnell, 1996; Herrington, 2002). Já o ângulo Q é utilizado como uma estimativa do vetor de força resultante entre o tracionamento do quadríceps e o ligamento patelar (Powers, 2003).

Powers e Hampton (1995) encontraram um varo do retropé aumentado nos pacientes com SPF quando medido em cadeia cinética aberta e em posição neutra da subtalar, sugerindo que o varo do retropé seria um fator de risco para a SPF por acarretar um aumento 
da pronação da subtalar em cadeia cinética fechada. No entanto, quando a postura do retropé foi avaliada em ortostatismo, como no presente estudo, Levinger e Gilleard (2004) encontraram um aumento do valgo do retropé em sujeitos com SPF, enquanto outros autores não encontraram associação entre a postura do retropé e a ocorrência da SPF (Messier et al., 1991; Thomee et al., 1995).

A estabilidade médio-lateral da patela é garantida por estabilizadores transversos e Iongitudinais. Os estabilizadores transversos são os retináculos medial (submetido à tração do músculo vasto medial) e lateral (submetido à tração do músculo vasto lateral e trato ileotibial). Os estabilizadores longitudinais são: o tendão do quadríceps acima e ligamento patelar abaixo. Fisiologicamente, os vetores de forca decorrentes das trações em direções opostas do tendão do quadríceps e ligamento patelar não são lineares, portanto a patela tende a ser tracionada lateralmente. Clinicamente, essa incongruência entre os vetores é conhecida como ângulo do quadríceps ou ângulo $Q$, sendo medido por meio de uma linha entre a espinha ilíaca ântero-superior e o centro da patela e outra linha que vai do centro da patela à tuberosidade da tíbia (Powers, 2003) (Figura 1).

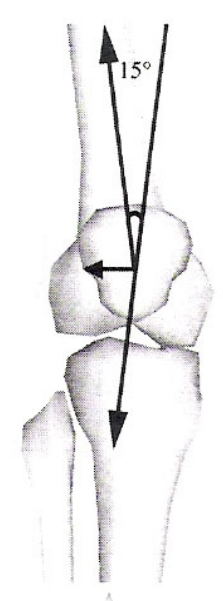

Figura 1. Representação do ângulo do quadríceps (acima = vetor do tendão do quadríceps, abaixo $=$ vetor do ligamento patelar, horizontal $=$ vetor lateral resultante da contração do músculo quadríceps) (Adaptado de Powers, 2003). 
No que diz respeito ao ângulo $Q$, apesar de ser a mais estudada entre as três medidas clínicas avaliadas neste estudo, não existe uma relação consistente entre o aumento do ângulo Q e a ocorrência da SPF (Livingston, 1998; Fredericson e Yoon, 2006).

Segundo Bevilaqua-Grossi (2007), existe uma grande variabilidade dos valores encontrados para o ângulo $Q$ na literatura, não havendo um consenso sobre os valores de normalidade ou anormalidade para esta mensuração e esta falta de consistência dos dados relativos ao ângulo $Q$ pode estar associada à falta de critérios metodológicos utilizados.

Além disto, trata-se de uma medida bastante sensível à erros de mensuração principalmente do centro da patela e tuberosidade da tíbia, onde estes pontos anatômicos devem ser definidos com uma acurácia de menos de $2 \mathrm{~mm}$ para o erro da medida do ângulo Q permanecer abaixo de 5 graus (France e Nester, 2001).

$\mathrm{Na}$ literatura encontram-se estudos que avaliaram os sujeitos em diferentes posições como, por exemplo, decúbito dorsal com os joelhos em extensão total com quadríceps relaxado(Nissen et al., 1998) assim como em ortostatismo (Melo de Paula et al., 2004; Emami et al., 2007). (Woodland e Francis, 1992) encontraram maiores valores do ângulo $Q$ quando medido na posição ortostática em relação à mensuração em decúbito dorsal.

Com relação à orientação médio-lateral da patela, por meio da medida descrita por Mc Connell (Figura 2), apesar de bastante difundida na clínica (McConnell, 1996; Herrington, 2002), a maioria dos estudos realizados até então tiveram como objetivo verificar a confiabilidade e validade da medida (Wilson, 2007). 


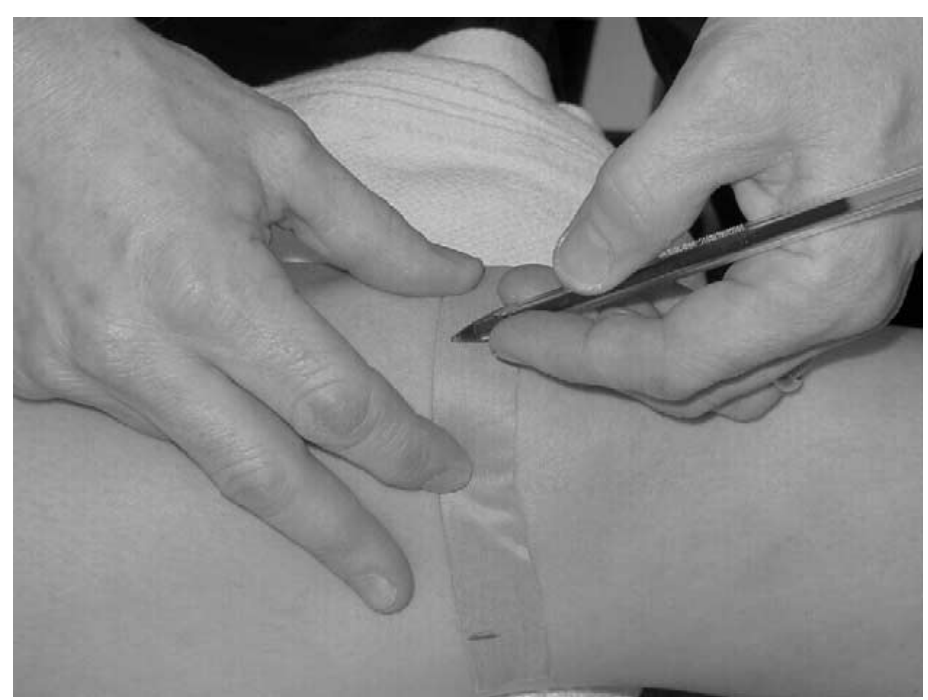

Figura 2. Medida da orientação médio-lateral da patela (Adaptado de Herrington,2002)

Powers et al. (1999), em um estudo de validade baseada em critério, concluiu que a medida clínica super estima a lateralização da patela em relação à medida obtida pela ressonância magnética, ou seja, a média de lateralização da patela encontrada por meio da medida clínica foi mais de duas vezes maior do que a encontrada na avaliação pela ressonância magnética. Por outro lado, Herrington (2002) encontrou uma boa concordância entre os resultados obtidos pela medida clínica e a medida por meio da ressonância magnética $(r=0,90)$.

Até o momento, um estudo teve como objetivo comparar esta medida clínica entre sujeitos com e sem SPF. Neste estudo tanto os sujeitos com SPF quanto os indivíduos assintomáticos apresentaram patelas lateralizadas, no entanto a quantidade de lateralização foi maior para os sujeitos com a disfunção (Herrington, 2008).

Neste sentido, tornam-se importantes estudos que avaliem a associação entre medidas comumente empregadas na clínica e a ocorrência da SPF utilizando-se de uma 
amostra adequada para se discutir as inferências dos resultados, na busca de se construir uma abordagem clínica fisioterapêutica da SPF baseada em evidências.

\subsection{Distúrbios no alinhamento dinâmico dos membros inferiores e Síndrome da Dor Patelofemural}

Os distúrbios no alinhamento dinâmico dos membros inferiores mais relacionados com a SPF na literatura são a pronação excessiva do retropé e o aumento da rotação mediall do quadril durante as atividades motoras (Powers, 2003).

Estudos sugerem que a fraqueza ou retardo na ativação dos músculos rotadores laterais e abdutores do quadril, levariam a um aumento na rotação medial desta articulação, lateralizando a patela em relação ao fêmur e aumentando as pressões na articulação patelofemural (Ireland et al., 2003; Robinson e Nee, 2007). Estudos que avaliaram tratamentos para SPF com ênfase na musculatura do quadril têm apresentado resultados favoráveis (Mascal et al., 2003; Nakagawa et al., 2008).

A associação entre a pronação excessiva do retropé e a SPF tem sido corroborada pelos resultados positivos de estudos que avaliaram os efeitos das órteses sob a forma de palmilhas construídas com o objetivo de reduzir o movimento de pronação excessiva no tratamento da dor em indivíduos com SPF (Saxena e Haddad, 2003; Johnston e Gross, 2004).

Segundo Gross e Foxworth (2003), os estudos realizados para verificar os efeitos clínicos das palmihas "anti - pronação", apesar de ainda serem escassos, mostram uma tendência da efetividade deste tipo de tratamento em pacientes com SPF. 
Bizzini et al. (2003) realizaram uma revisão sistemática objetivando avaliar a qualidade de ensaios clínicos randomizados em diversos tipos de intervenções na SPF. Neste estudo, no que se refere ao uso de palmilhas foi incluído o estudo de Eng e Pierrynowsky (1993), a partir do qual foi possível concluir que o tratamento com palmilhas pode ser efetivo na redução da dor em pacientes com SPF.

Eng e Pierrynowsky (1993) realizaram um ensaio clínico randomizado com o objetivo de investigar a efetividade das palmilhas como tratamento coadjuvante na SPF. Foram avaliadas 20 adolescentes do sexo feminino, com SPF e retropé valgo e / ou antepé varo acima de $6^{\circ}$. Realizaram-se 16 sessões de fisioterapia baseada em exercícios com o grupo controle e o grupo de tratamento, enquanto o grupo de tratamento - além dos exercícios usou palmilhas, de acordo com o grau de valgo de retropé ou varo de antepé encontrado. 0 grupo de tratamento obteve uma redução significativa da dor, principalmente em atividades que envolviam descarga de peso como correr, subir / descer escadas e agachar.

O embasamento teórico para o uso de palmilhas no tratamento da SPF, é que as palmilhas são capazes de alterar a cinemática do complexo pé e tornozelo, produzindo consequentemente mudanças nos movimentos do joelho que influenciam a mecânica articular da patelofemural (Gross e Foxworth, 2003).

Esta premissa vai ao encontro de outro estudo (Eng e Pierrynowski, 1994) onde foram avaliados os efeitos das palmilhas na cinemática tridimensional do complexo pétornozelo e joelho na marcha e corrida em pacientes com SPF. Foram analisados 10 sujeitos em três momentos da fase de apoio na marcha e corrida nas situações com e sem palmilha calçando tênis. Os resultados mostraram que não houve reduções de movimentação significativas em nenhuma situação no plano sagital do tornozelo e joelho. Todavia foram observadas reduções significativas do movimento no plano frontal do retropé no contato 
inicial e médio-apoio na marcha e durante o contato inicial e a propulsão na corrida. As palmilhas também reduziram o movimento do retropé no plano transversal na fase propulsiva da marcha e corrida. No joelho, houve uma redução do movimento no plano transversal no contato inicial da marcha. No plano frontal, ocorreu uma redução do movimento no contato inicial da marcha, mas aumento no contato inicial e médio apoio da corrida. Para esses autores, reduções entre $0,8^{\circ}$ e $2^{\circ}$ no valgo do retropé parecem reduzir o movimento na articulação do joelho nos planos transversal e frontal, portanto, essa relação direta experimental estaria de acordo com os resultados clínicos obtidos no uso de palmihas em SPF. No entanto, reduções acima de 2,50 sugerem aumento na movimentação do joelho por mecanismos de compensação em atividades de maior sobrecarga - corrida, por exemplo sugerindo cautela com relação à magnitude de redução de pronação oferecida pela palmilha.

Hipóteses teóricas de como a pronação excessiva pode influenciar a disfunção da articulação patelofemoral têm sido propostas, com o objetivo de esclarecer a etiologia multifatorial da SPF e consequentemente melhorar a sua abordagem terapêutica. Durante a pronação fisiológica, o calcâneo everte e a cabeça do talus desliza medialmente e inferiormente, resultando em uma rotação medial do talus. Devido à relação intrínseca entre o talus e a tíbia na articulação tíbio-tarsica, a tíbia roda medialmente (Powers et al., 2002).

Segundo Tibério (1987) e Powers (2003), uma excessiva e/ou prolongada pronação, teoricamente levaria a uma excessiva rotação medial da tíbia. Esta rotação medial excessiva da tíbia induziria uma rotação medial do fêmur para manter a relativa rotação lateral do platô tibial em relação aos côndilos femorais, associada com a extensão do joelho na fase de médio apoio na marcha. Este aumento da rotação medial do fêmur ampliaria o ângulo $Q \mathrm{e}$ consequentemente as forças laterais que tracionam a patela no plano frontal acrescendo as forças de contato e forças de pressão na articulação patelofemural. 
A pronação excessiva, também tem sido relacionada ao aumento do valgo fisiológico do joelho, que assim como a rotação medial da extremidade inferior descrita acima pode aumentar o ângulo $Q$ e majorar as forças compressivas na porção lateral da patelofemural (Powers, 2003; La Botz, 2004).

La Botz (2004) sugere uma "cascata patofisiológica" onde a pronação excessiva leva ao aumento da rotação medial da tíbia e conseqüentemente ao aumento do valgo fisiológico do joelho (Figura 3).

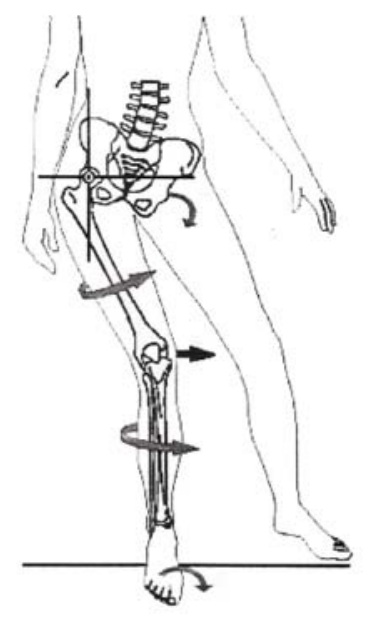

Figura 3. Esquema da cascata patofisiológica onde a pronação excessiva pode levar à rotação medial dos membros inferiores e aumento do valgo fisiológico do joelho ( Adaptado de Powers, 2003).

Alguns estudos biomecânicos foram realizados para avaliar a relação entre a pronação excessiva do retropé e a SPF de forma experimental. No entanto, os resultados destas pesquisas têm se mostrado controversos (Messier et al., 1991; Powers et al., 2002; Earl et al., 2005; Levinger e Gilleard, 2007).

Messier et al. (1991) avaliaram 36 corredores, 14 homens e 6 mulheres no grupo com SPF e 12 homens e 4 mulheres no grupo controle. A cinemática do retropé foi avaliada simultaneamente com a força reação do solo em uma plataforma de força durante a corrida 
com calçado. As variáveis analisadas foram o ângulo do ataque do calcanhar, pronação máxima, tempo para alcançar a pronação máxima, movimento total do retropé e velocidade máxima de pronação. Não foram encontradas diferenças significativas entre os grupos nas variáveis estudadas. Neste estudo, no entanto, avaliou-se somente a corrida na velocidade de treino com tênis, nenhuma outra situação foi proposta para se comparar possíveis modificações no movimento do retropé entre os grupos. Estes autores concluíram que segundo seus resultados, a pronação excessiva não é um fator etiológico significativo no desenvolvimento da SPF, mas que enquanto futuros estudos não confirmem estes dados, a quantificação da pronação deve permanecer na avaliação clínica dos corredores com SPF.

Powers et al. (2002) avaliaram 42 mulheres, com idades entre 15 e 47 anos, sendo 24 no grupo experimental com SPF e 18 no grupo controle. O objetivo do estudo foi comparar a magnitude e tempo de pronação na marcha descalça em uma velocidade auto-selecionada entre os grupos. Para tanto, foi utilizado um sistema de análise cinemática composto por seis câmeras infra-vermelhas (VICON). Foram usados foot switches para avaliar as características das passadas e os padrões de contato com o solo. 0 pé foi modelado como um segmento único, na intenção de se obter uma indicação da pronação total do pé. Não foram encontradas diferenças significativas entre os grupos nas variáveis analisadas. Segundo os autores, uma limitação do estudo foi que ao modelar o pé como um único segmento não foi possível distinguir os movimentos do retropé dos movimentos do antepé. Além disto, os indivíduos com SPF apresentaram uma velocidade reduzida da marcha em relação ao grupo controle. Portanto, fica a incógnita se em uma velocidade maior, alterações na cinemática do pé no grupo experimental poderiam ocorrer.

Outro estudo avaliou 25 mulheres com idade média de 36 anos, sendo 11 do grupo SPF e 14 do grupo controle. $O$ objetivo foi analisar a posição do retropé em relação à tíbia no 
toque do calcanhar na fase de apoio da marcha em velocidade auto selecionada com os indivíduos descalços. Foram usadas quatro câmeras de vídeo a $50 \mathrm{~Hz}$ para obter os dados cinemáticos em 2D e a transformação linear direta foi usada para se obter dados em 3D. Marcadores externos retro refletivos foram usados para avaliar o movimento do retropé em relação à tíbia. A cinemática foi coletada simultaneamente com os dados cinéticos obtidos por uma plataforma de força a uma freqüência de $100 \mathrm{~Hz}$. Os resultados mostraram diferença significativa entre os grupos na cinemática do retropé no plano frontal. 0 grupo controle apresentou inversão, enquanto o grupo experimental apresentou eversão do retropé no momento do toque do calcanhar na fase de apoio da marcha. A velocidade da marcha foi igual para ambos os grupos. Portanto, esses resultados são controversos com relação aos dois estudos anteriores, indo ao encontro das propostas teóricas sobre a relação entre pronação excessiva e a SPF (Levinger e Gilleard, 2005).

Earl et al. (2005) avaliaram a pronação dinâmica do retropé por meio da cinemática em 32 indivíduos com e sem diagnóstico de SPF na tarefa de descida lateral de um "step". Os resultados mostraram que a pronação dinâmica máxima foi significativamente maior no grupo com diagnóstico de SPF.

A partir da discussão da literatura, podemos constatar que a relação entre a pronação excessiva do retropé e a SPF é bastante divulgada na clínica, de certo modo embasada pelos resultados positivos encontrados no uso de palmilhas anti-pronação como tratamento coadjuvante de indivíduos que sofrem com esta disfunção bastante comum. Teorias têm sido propostas com o objetivo de esclarecer esta relação e consequentemente melhorar sua abordagem terapêutica. No entanto, os resultados de estudos empíricos biomecânicos têm se mostrado controversos. 
Segundo Cheung et al. (2006) são necessárias mais evidências provenientes de estudos biomecânicos e clínicos para se justificar o uso de calçados que controlem a movimentação do pé na reabilitação da SPF.

\subsection{Distribuição da pressão plantar e a Síndrome da Dor Patelofemural}

Segundo Orlin e McPoil (2000) apesar da análise da distribuição da pressão plantar ser usualmente reconhecida como um importante elemento na avaliação de pacientes diabéticos neuropatas, dados provenientes deste método de avaliação também podem ser bastante úteis no diagnóstico e evolução dos tratamentos de afecções musculoesqueléticas. Sendo assim, padrões atípicos de distribuição de pressão plantar podem refletir disfunções ou fatores de risco de para disfunções musculoesqueléticas dos membros inferiores.

A análise da distribuição da pressão plantar possibilita inferências da função do pé e tornozelo na marcha, assim como em outras atividades funcionais, pois o pé e o tornozelo fornecem simultaneamente o suporte e a flexibilidade necessários à execução das tarefas locomotoras (Orlin e McPoil, 2000). Sendo assim, observa-se que o padrão de distribuição da pressão plantar do pé durante a fase de apoio da marcha - assim como de outras atividades locomotoras - mantém uma relação estreita com a movimentação articular do complexo pé tornozelo (Perry, 2005).

Segundo Perry (2005), quando ocorre a pronação excessiva do retropé, observamos modificações nos padrões de contato do pé com o solo, onde o contato inicial se dá com a superfície medial do calcanhar, por exemplo. Esta afirmação está de acordo com os achados de um estudo biomecânico prospectivo de análise da marcha por meio da cinemática e distribuição da pressão plantar em 400 sujeitos e que investigaram os fatores de risco para 
lesões nos membros inferiores relacionadas ao estresse na prática de exercícios. Neste estudo, os autores observaram que a pressão plantar e os dados cinemáticos mostraram as mesmas tendências onde os indivíduos que desenvolveram lesões, possuíam um contato inicial do calcanhar significativamente mais central na distribuição da pressão plantar, acompanhado de uma maior pronação do retropé no dados cinemáticos quando comparados aos indivíduos que não desenvolveram lesões. Além disto, segundo os autores, as variáveis de distribuição de pressão plantar foram os dados que melhor discriminaram os indivíduos lesados dos não lesados(Willems et al., 2006).

Thijs et al. (2007) avaliaram prospectivamente a pressão plantar de militares, com o objetivo de encontrar fatores de risco para a SPF, encontrando associação entre a SPF e alteração no rolamento do pé durante a marcha descalça. Neste estudo, os indivíduos que desenvolveram SPF apresentaram uma distribuição mais lateralizada da pressão plantar durante o contato inicial e um rolamento do pé mais lateral quando comparados aos indivíduos que não desenvolveram SPF. Segundo os autores, estes achados sugerem que durante a marcha descalça, os indivíduos que desenvolveram SPF apresentaram um contato inicial do calcanhar em uma posição menos pronada e efetuaram o rolamento do pé mais lateralmente do que os indivíduos controle.

Apesar da importância deste estudo, por abordar o rolamento dos pés durante a marcha como fator de risco para a SPF, avaliou-se uma população específica de militares, predominantemente do sexo masculino, que estavam passando por um intenso período de atividade física, limitando a generalização dos resultados.

Thijs et al (2008) avaliaram a pressão plantar durante a corrida descalça em corredores iniciantes para determinar fatores de risco para SPF relacionados à corrida. Foram avaliadas as forças verticais e médio-laterais, assim como os impulsos absolutos e relativos 
de oito áreas do pé. Neste estudo prospectivo, os indivíduos que desenvolveram SPF apresentaram uma diminuição do tempo para se atingir o pico de força vertical no retropé lateral e um maior pico de força vertical no segundo metatarso. Segundo estes autores, a SPF está relacionada à um aumento do impacto no contato inicial e na propulsão durante a corrida.

\subsection{A tarefa de descer escadas e a Síndrome da Dor Patelofemural}

Os estudos citados anteriormente foram desenvolvidos durante a marcha e a corrida. A avaliação de tarefas motoras mais desafiadoras como, por exemplo, subir ou descer escadas pode contribuir para o entendimento de mecanismos compensatórios que não são observados no andar que é uma tarefa bastante automatizada e habituada aos ambientes e situações que os sujeitos enfrentam no dia a dia.

As forças de reação compressivas da articulação patelofemural dependem dos vetores de força do tendão do quadríceps superiormente e do ligamento da patela inferiormente. Esses dois vetores podem ser decompostos em um vetor resultante que é responsável pela compressão da patela no fêmur. A magnitude desse vetor resultante aumenta com o aumento da força do vetor do quadríceps e com a flexão do joelho (La Botz, 2004) (Figura 4). No descer escadas, ocorre a ação excêntrica do músculo quadríceps associada à flexão do joelho levando ao aumentando das forças compressivas na articulação patelofemoral (Katchburian et al., 2003). Estes fatores podem explicar porque descer escadas é frequentemente citada como uma atividade de vida diária relacionada ao surgimento ou agravamento da dor para os pacientes com SPF. Na fase de apoio da marcha, onde o joelho flete por volta de 10 a15, a força de reação articular na patelofemural é de $50 \%$ do peso 
corporal. Na atividade de descer escadas, esta força sobe para 3,3 do peso corporal (Neumann, 2002)

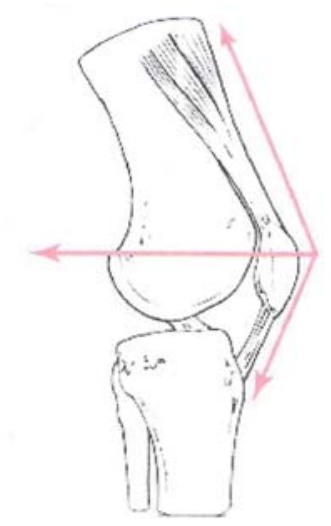

Figura 4. Vetores de força da articulação patelofemural (acima = vetor do tendão do quadríceps, abaixo $=$ vetor do ligamento patelar, horizontal $=$ vetor resultante responsável pela compressão da patela no fêmur) (Adaptado de La Botz, 2004).

Brechter e Powers (2002) encontraram uma redução da flexão e do momento extensor do joelho em indivíduos com SPF no descer escadas caracterizando uma provável estratégia de proteção nestes indivíduos durante esta tarefa. Uma diminuição da cadência também foi encontrada nos sujeitos com SPF, confirmando a maior cautela assumida em tarefas desafiadoras.

Brechter e Powers (2002) e Levinger e Gileard (2007)mencionaram a dificuldade em se diferenciar um mecanismo biomecânico intrínseco de uma estratégia de proteção adotada por causa da dor que a tarefa motora provoca nos sujeitos com SPF. Levinger e Gileard (2007) encontraram uma diminuição das forças de reação do solo em sujeitos com SPF na marcha, discutindo que não ficou claro durante o estudo se as alterações biomecânicas encontradas foram uma estratégia de proteção para evitar a dor ou um fator de risco inerente. Estes autores sugeriram que a influência da dor nos padrões biomecânicos durante tarefas mais desafiadoras e que aumentam a sintomatologia em pacientes com SPF deve ser investigada. 
A avaliação da Escala Visual Analógica de Dor (EVA) antes e após a avaliação da distribuição da pressão plantar no descer escadas pode contribuir para esclarecer a relação entre a dor e os padrões biomecânicos nesta tarefa, na medida em que pode quantificar a intensidade da dor após a tarefa realizada (Williamson e Hoggart, 2005).

A hipótese inicial deste estudo é que a SPF está associada ao aumento do valgo do retropé, ao aumento do ângulo $Q$, e à lateralização da patela na avaliação postural do retropé e joelho. Além disto, hipotetiza-se que o GSPF deve apresentar um apoio medializado nas tarefas locomotoras avaliadas. Esta hipótese baseia-se no fato de que esta disfunção pode estar associada à uma excessiva pronação do retropé assim como um aumento da rotação medial do quadril o que levaria à uma excessiva rotação medial dos membros inferiores nas tarefas motoras do cotidiano e consequentemente à uma geometria de apoio dos pés no solo mais medial. Este apoio mais medial resultaria em maiores pressões e área de contato nas regiões mediais dos pés na avaliação da pressão plantar do descer escadas e da marcha. 


\section{MÉTODOS}

Este estudo teve um delineamento observacional, transversal caso-controle e foi desenvolvido no Laboratório de Biomecânica do Movimento e Postura Humana do Depto. de Fisioterapia, Fonoaudiologia e Terapia Ocupacional da Faculdade de Medicina para responder três objetivos distintos, portanto, foi organizado em três experimentos (Figura 5).

A casuística, os critérios de inclusão e exclusão da amostra foram comuns a todos os três experimentos e, portanto serão descritos como único para todos os experimentos. Porém o tamanho amostral, as características antropométricas e demográficas das amostras de cada experimento foram distintas e, portanto, serão descritas dentro de cada experimento correspondente.

O instrumento utilizado para a avaliação da pressão plantar foi comum para os experimentos 2 e 3 portanto será descrito com detalhes no experimento 2. As variáveis de análise e a análise estatística também foram distintas entre os experimentos e serão descritas individualmente. 


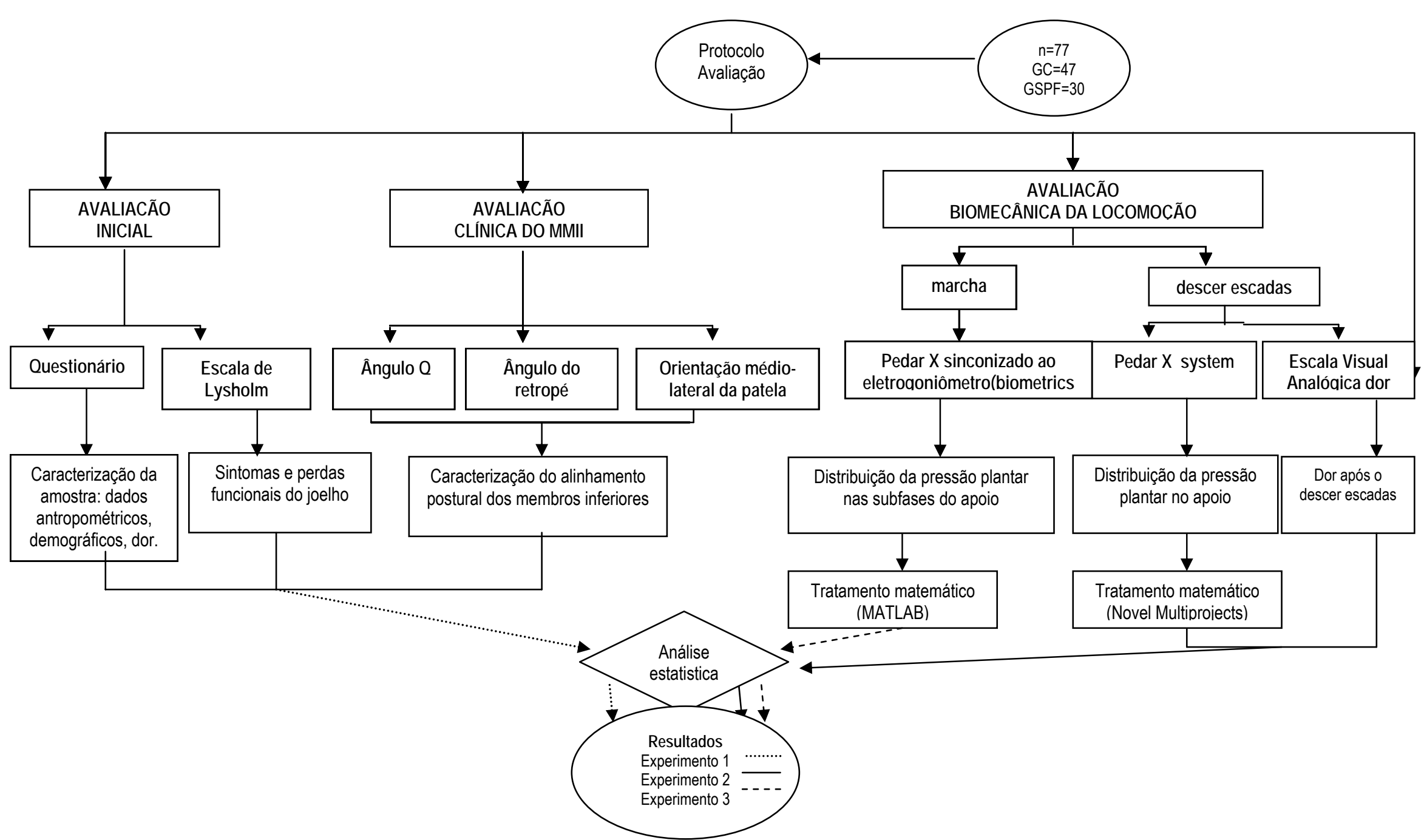

Figura 5. Fluxograma do protocolo de avaliação dos 3 experimentos 


\subsection{Casuística dos 3 experimentos}

Foram estudados indivíduos adultos de ambos os sexos entre 18 e 45 anos. Todos os sujeitos assinaram um termo de consentimento livre e esclarecido (ANEXO 1) aprovado pelo Comissão de Ética para Análise de Projetos de Pesquisa da Diretoria Clínica do Hospital das Clínicas da Faculdade Medicina da Universidade de São Paulo (protocolo no 1237/05) (ANEXO 2).

O cálculo amostral foi feito com base em consulta ao Instituto de Matemática e Estatística da Universidade de São Paulo estimando uma proporção de 30\% para desenvolvimento da SPF, $80 \%$ de poder estatístico e erro do tipo I de 5\% (Breslow e Day, 1980; Breslow e Day, 1987).

A amostra total foi composta de 77 adultos jovens divididos em dois grupos: grupo controle (GC=47) e grupo com Síndrome da Dor Patelofemural (GSPF=30).

Os sujeitos do GSPF foram encaminhados pelo Ambulatório de Ortopedia do Hospital Universitário da USP. Os critérios de inclusão para este grupo foram diagnóstico de SPF há no mínimo dois meses e que os sinais e sintomas surgiam ou eram exacerbados por pelo menos duas das seguintes situações: contração resistida do quadríceps femoral, agachar-se, permanecer sentado por longos períodos, descer ou subir escadas. Os critérios de exclusão para o GSPF foram: história ou queixa atual de outra disfunção musculoesquelética nos joelhos(Salsich e Perman, 2007).

Os critérios de inclusão para o GC foram indivíduos assintomáticos e similares em idade, sexo e características antropométricas ao GSPF. Para tanto, a coleta de dados com o GSPF foi realizadas em primeiro lugar, para que fosse possível selecionar o GC posteriormente. Os critérios de exclusão para o GC foram: história de dor nos joelhos com 
mais de dois meses de duração, ou mais de dois episódios de dor no joelho durante o último ano.

Para ambos os grupos os critérios de exclusão foram discrepância de membros inferiores acima de 1cm (Eng e Pierrynowski, 1994), cirurgia prévia do joelho ou lesão musculoesquelética nos membros inferiores e coluna lombar nos últimos três meses (Sacco et al., 2007), assim como doenças sistêmicas ou neurológicas que pudessem comprometer a locomoção.

Inicialmente, 34 sujeitos com SPF foram previamente selecionados para serem avaliados, no entanto foram excluídos quatro sujeitos por apresentarem lesão no menisco medial, lombalgia aguda, cirurgia prévia ligamentar no joelho e tendinite patelar associados ao diagnóstico de SPF.

\subsection{Avaliação inicial dos 3 experimentos}

Assim que o indivíduo chegava ao laboratório, depois de assinado o termo de consentimento, era aplicado um questionário previamente elaborado por meio de entrevista para caracterização dos sujeitos e esclarecimentos dos critérios de exclusão. Este questionário foi dividido em 3 itens: Dados pessoais; Características Antropométricas; Dados sobre Atividade Física (ativo ou não, tipo de atividade praticada, tempo de prática, freqüência)(Shephard, 2003).

Em seguida foi aplicada a Escala Funcional do Joelho de Lysholm com o objetivo de classificar o grau de perda funcional do joelho dos indivíduos com a disfunção (ANEXO 3). A Escala de Avaliação do Joelho de Lysholm está dentro da categoria de questionários que objetivam avaliar os sintomas subjetivos (instabilidade, dor, falseio) bem como a perda 
funcional do joelho nas atividades de vida diária (Lysholm e Gillquist, 1982). Esta escala foi inicialmente elaborada para a avaliação funcional na instabilidade anterior do joelho por lesão ligamentar, no entanto ela tem sido usada para a avaliação da perda funcional do joelho na SPF (Natri et al., 1998)Esta escala é composta de oito itens que quando somados permitem a classificação da função do joelho em quatro categorias: Excelente (95 a 100 pontos), Bom (84 a 94 pontos), Regular (65 a 83 pontos) e Pobre (menos que 64 pontos) 


\section{EXPERIMENTO 1}

\subsection{Objetivo}

Verificar se existe associação entre o alinhamento postural do retropé, o ângulo $Q$, assim como a orientação médio-lateral da patela e a SPF.

\subsection{Casuística e Métodos do Experimento 1}

Casuística

A partir de cálculo amostral, a amostra foi constituída por 77 adultos de ambos os sexos. O GC foi composto de 47 sujeitos, sendo 42 mulheres com idade de $29 \pm 6$ anos, estatura de $164 \pm 8 \mathrm{~cm}$ e massa $59 \pm 9 \mathrm{~kg}$. O GSPF foi composto de 30 sujeitos, sendo 26 mulheres com $30 \pm 7$ anos, estatura de $165 \pm 9 \mathrm{~cm}$ e massa de $63 \pm 11 \mathrm{~kg}$. O GSPF apresentou mediana de 68 pontos na Escala Funcional do Joelho de Lysholm. Os grupos foram semelhantes quanto à porcentagem de indivíduos fisicamente ativos (GC=51,1\%, $\mathrm{GSPF}=41,4 \% ; p=0,508)$, tempo de prática em anos $(\mathrm{GC}=5 \pm 5$ anos, $G S P F=3 \pm 4$ anos; $p=0,817)$, freqüência em dias por semana ( $G C=3 \pm 1$ dias/sem, $G S P F=3 \pm 1$ dias por semana; $p=0,177)$ e duração em minutos $(G C=85 \pm 38 \mathrm{~min}, G S P F=67 \pm 2 \min , p=0,419)$ da atividade física praticada. 
Medidas Clínicas

O ângulo do retropé e o ângulo $Q$ foram mensurados por meio da fotogrametria digital (Sacco et al., 2007) com auxílio do Software SAPO v.0.67 (Software para Avaliação Postural), enquanto que a orientação médio-lateral da patela foi medida pelo método descrito por McConnell (McConnell, 1996; Herrington, 2002).

A fotogrametria é um recurso que permite a quantificação do alinhamento postural, fornecendo informação de boa confiabilidade intra e inter-examinadores, desde que cuidados metodológicos sejam seguidos para se padronizar as fotos e minimizar efeitos de distorção (lunes et al., 2005).

Para a mensuração do ângulo $Q$ foram palpados: espinha ilíaca ântero-superior, centro da patela, tuberosidade da tíbia (plano frontal anterior). Para o cáculo deste ângulo, o vértice era o centro da patela que se unia à espinha ilíaca ântero-superior e tuberosidade da tíbia (figura 6). Para o ângulo do retropé foram utilizadas as referências anatômicas: ponto médio do terço póstero-inferior da perna, ponto médio da porção superior do calcâneo e ponto médio da porção inferior do calcâneo (plano frontal posterior) (Sacco et al., 2007). Para o cálculo desse ângulo, o vértice era o ponto médio da porção superior do calcâneo e unia-se ao ponto médio do terço póstero-inferior da perna e ao ponto médio da porção inferior do calcâneo. (figura 7). Estes pontos anatômicos foram palpados e em seguida marcados com etiquetas vermelhas auto-adesivas de 0,9cm de diâmetro (Sacco et al., 2007). 


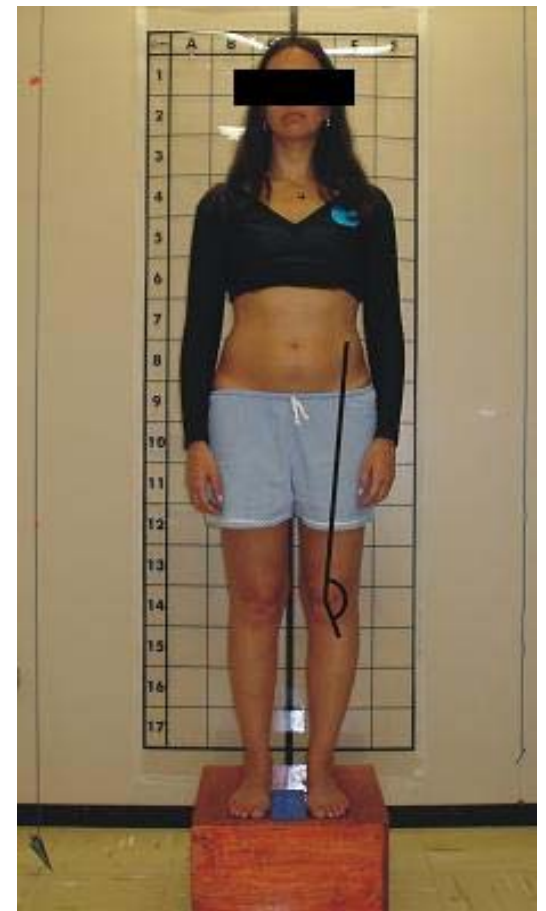

Figura 6. Representação do cálculo do ângulo Q por fotogrametria.

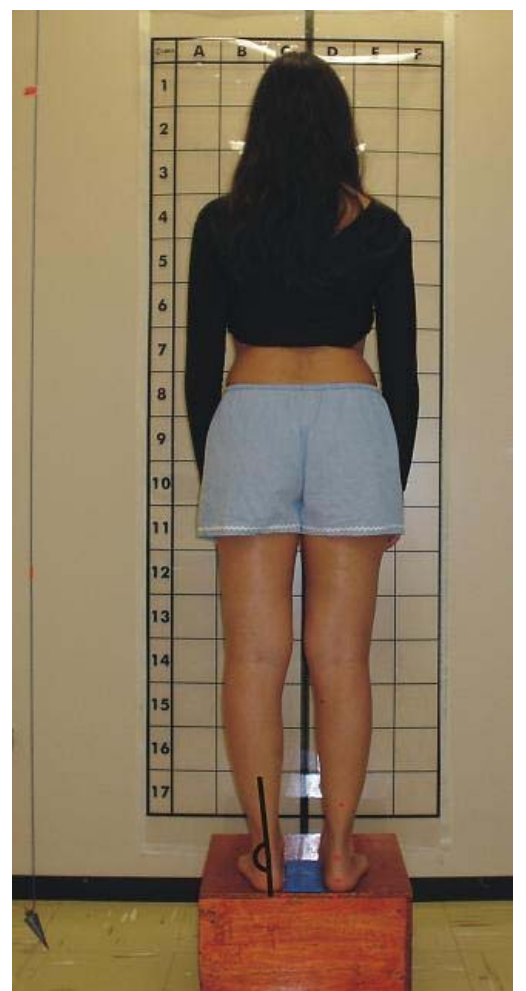

Figura 7. Representação do cálculo do ângulo do retropé por fotogrametria. 
O indivíduo encontrava-se em posição ortostática, sobre um banco de $20 \mathrm{~cm}$ de altura por $40 \mathrm{~cm}$ de comprimento e $40 \mathrm{~cm}$ de largura, posicionado a uma distância de $15 \mathrm{~cm}$ da parede com um fio de prumo pendurado no teto e ultrapassando os pés dos sujeitos posicionados. Também foi utilizado um retângulo de etil vinil acetato $(7 \mathrm{~cm}$ de largura $X 30 \mathrm{~cm}$ de comprimento) entre os pés de cada sujeito para que o posicionamento dos pés fosse mantido inter sujeitos.

Os sujeitos foram fotografados no plano frontal anterior e posterior utilizando-se uma câmara digital (1600 x 1200 pixels). A máquina fotográfica estava posicionada paralela ao chão a uma distância de 2,4 $\mathrm{m}$ do banco, sobre um tripé nivelado a uma altura de $0,7 \mathrm{~m}$, à altura do joelho. $O$ cálculo fotogramétrico dos ângulos de interesse foi realizado por meio do software SAPO v.0.67 (Sacco et al., 2007).

Os ângulos $Q$ foram classificados como diminuídos quando se apresentavam menores do que 11 graus (homens) ou 13 graus (mulheres); normais entre 11 e 15 graus (homens) ou 13 e 17(mulheres); e finalmente aumentado acima de 15 graus (homens) ou 17 graus (mulheres) (Woodland e Francis, 1992). Os retropés foram classificados como varos quando 0 ângulo do retropé era menor do que 0 grau; valgo entre 0 e 6 graus e valgo aumentado acima de 6 graus(Eng e Pierrynowski, 1994).

A medida da orientação médio-lateral da patela foi realizada adaptando-se o método descrito por McConnell (McConnell, 1996; Herrington, 2002). Os sujeitos foram posicionados decúbito dorsal com o joelho estendido (Powers et al., 1999). Esta medida foi descrita originalmente com 0 joelho em $20^{\circ}$ de flexão, no entanto Herrington (2008) destacou a importância da avaliação em outros graus, sendo que ainda não está estabelecida a melhor posição para se avaliar esta medida, com o objetivo de verificar a sua associação com a SPF. Os epicôndilos medial e lateral do joelho e o centro da patela foram palpados e marcados em 
uma fita de alumínio posicionada transversalmente ao joelho dos participantes. Este procedimento foi realizado três vezes repetindo-se inclusive a palpação dos pontos anatômicos. Em seguida, as distâncias entre os epicôndilos medial e lateral e o centro da patela marcados na fita foram mensuradas. A distância lateral foi subtraída da medial, ou seja, valores positivos indicavam patela lateralizada, negativos indicavam patela medializada, enquanto valores iguais a zero eram computados como patelas centralizadas. Em seguida a média das três mensurações foi calculada(Herrington, 2002). Todo o procedimento foi realizado pelo mesmo avaliador.

Para as três medidas clínicas avaliadas, no GSPF foi avaliado o membro que apresentava dor (disfunções unilaterais) e o membro que apresentava maior dor (disfunções bilaterais). No GC, o membro avaliado foi escolhido aleatoriamente.

\section{Análise Estatística}

Confirmada a normalidade dos dados por meio do teste de aderência de Shapiro Wilks, as variáveis ângulo do retropé, ângulo $Q$ e orientação médio-lateral da patela foram comparadas entre os dois grupos por meio de 4 testes t para amostras independentes. Além disto, foi aplicado o teste qui-quadrado para múltiplas respostas com o objetivo de verificar a existência de associação entre as variáveis citadas acima e a SPF.

\subsection{Resultados do Experimento 1}

A tabela 1 mostra as médias e desvios padrão, assim como os resultados do teste $t$ para as medidas do ângulo do retropé, ângulo $Q$ e orientação médio-lateral da patela para 
ambos os grupos. Não foram observadas diferenças significativas entre os grupos para 0 ângulo do retropé, ângulo $Q$ e patelas lateralizadas. No entanto, observa-se que entre os indivíduos que apresentaram patelas medializadas, houve diferença significativa entre os grupos, onde o GSPF apresentou uma menor medialização da patela quando comparado ao GC.

Tabela 1. Médias, desvios padrão e valores do $p$ do ângulo do retropé ,ângulo $Q$ e medida da orientação médio-lateral da patela dos grupos com síndrome da dor patelofemural(GSPF) e controle (GC).

\begin{tabular}{lccc}
\hline & $\mathbf{G C}(\mathrm{n}=47)$ & $\mathrm{GSPF}(\mathrm{n}=30)$ & $\mathbf{p}^{1}$ \\
\hline ângulo do retropé (graus) & $5,3 \pm 4$ & $5,5 \pm 3$ & 0,303 \\
\hline ângulo Q (graus) & $17,9 \pm 6$ & $17,6 \pm 6$ & 0,623 \\
\hline patelas lateralizadas(mm) & $16,5 \pm 9$ & $13,3 \pm 8$ & 0,143 \\
\hline patelas medializadas(mm) & $-14,1 \pm 8$ & $-7,1 \pm 6$ & $0,047^{*}$ \\
\hline 1
\end{tabular}

${ }^{1}$ teste $t,{ }^{*}$ representa diferença significativa entre os grupos

As porcentagens de ângulo do retropé classificados como varo, valgo e valgo aumentado em ambos os grupos são apresentados na figura 8. O GSPF apresentou uma maior porcentagem de retropés valgos aumentados, enquanto que o grupo controle apresentou uma maior proporção de retropés valgos e varos, no entanto esta associação não se mostrou significativa pelo teste qui-quadrado para múltiplas respostas $(p=0,675)$. 


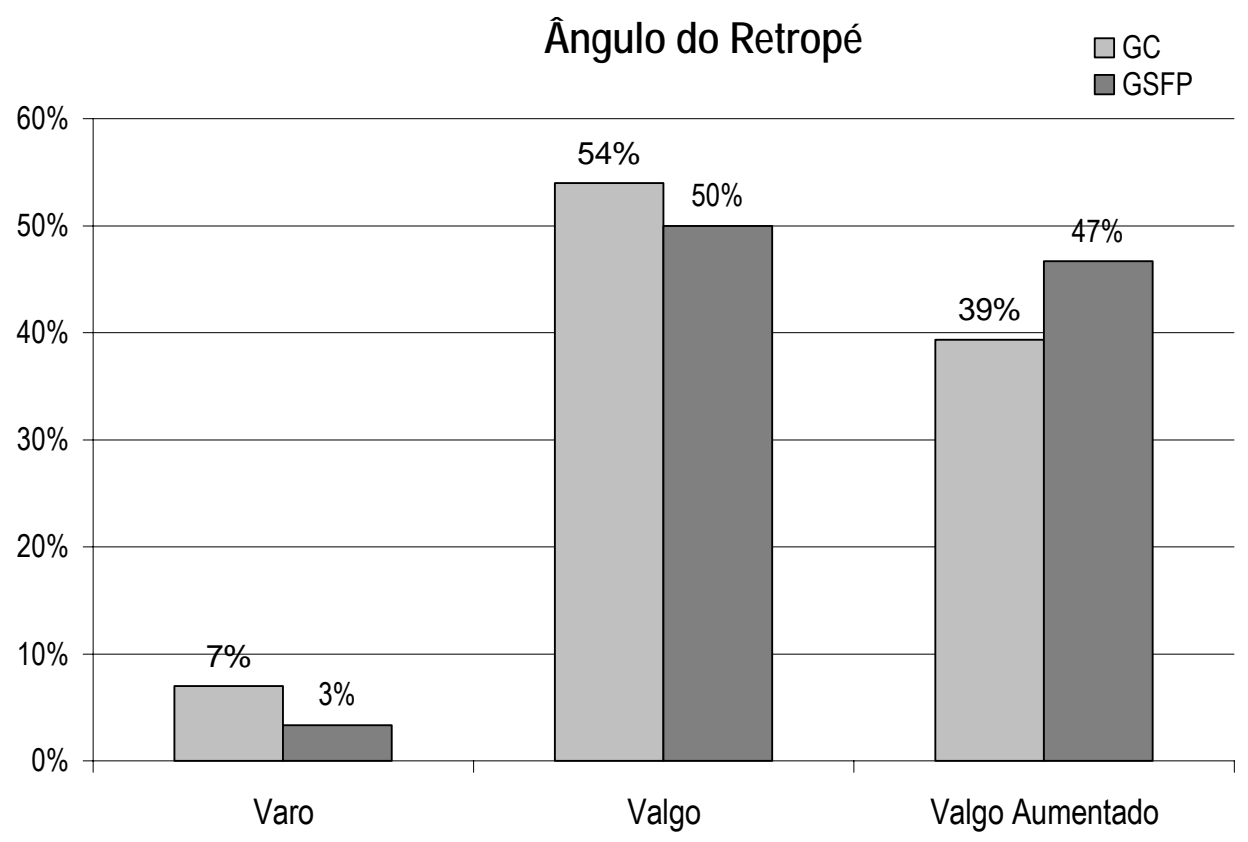

Figura 8. Distribuição das porcentagens de ângulos do retropé varos, valgos e valgos aumentado no grupo controle (GC) e no grupo síndrome da dor patelofemural (GSPF).

Na figura 9, observa-se as porcentagens de Ângulos $Q$ classificados como diminuídos, normais e aumentados em ambos os grupos, não havendo associação significativa entre a distribuição da classificação dos Ângulos $Q$ e a ocorrência de SPF analisada pelo teste qui-quadrado para múltiplas respostas $(p=0,490)$. Na observação qualitativa dos dados nota-se que o GSPF apresentou uma maior proporção de Ângulos $Q$ diminuídos e menor porporção de aumentados quando comparado ao GC. 


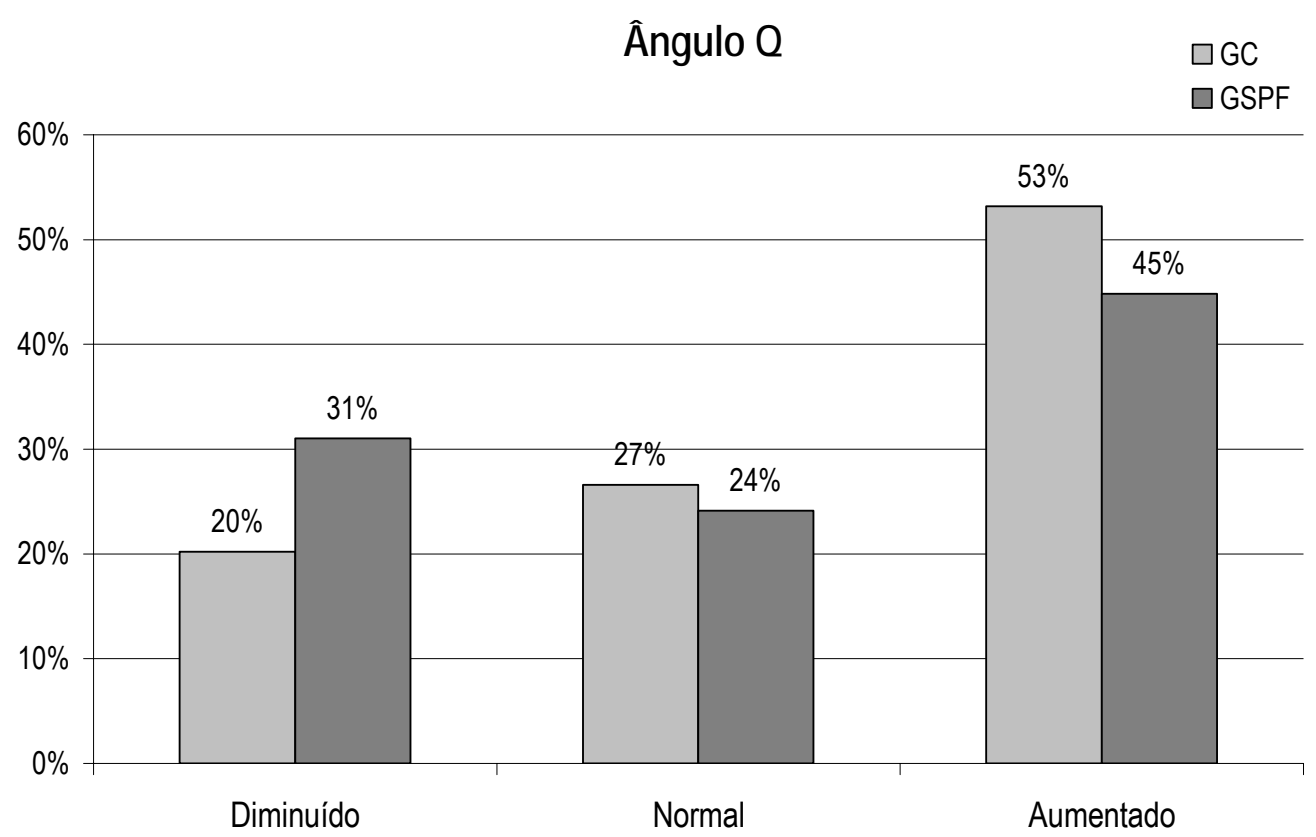

Figura 9. Distribuição das porcentagens de ângulos $Q$ diminuídos, normais e aumentados no grupo controle (GC) e no grupo síndrome da dor patelofemural (GSPF).

Na figura 10, observa-se as porcentagens de patelas medializadas, centralizadas e lateralizadas em ambos os grupos. O GSPF apresentou uma maior porcentagem de patelas lateralizadas, enquanto que o GC apresentou uma maior porcentagem de patelas centralizadas e medializadas, no entanto esta associação não se mostrou significativa pelo teste qui-quadrado para múltiplas respostas $(p=0,627)$. 


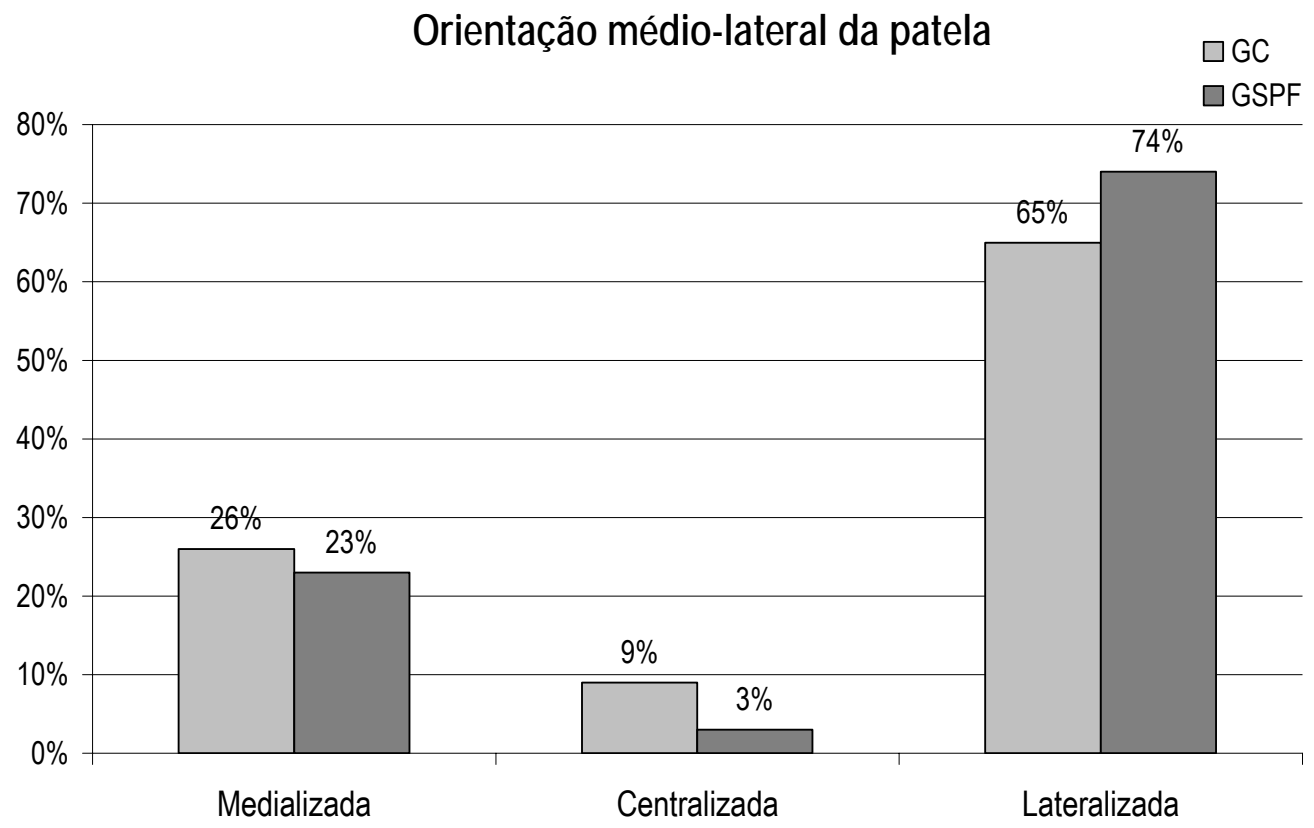

Figura 10. Distribuição das porcentagens de patelas medializadas, centralizadas e lateralizadas no grupo controle (GC) e no grupo síndrome da dor patelofemural (GSPF).

\subsection{Discussão do Experimento 1}

Este estudo teve como objetivo verificar se existe a associação entre o alinhamento postural do retropé, o ângulo $Q$, assim como a orientação médio-lateral da patela e a SPF.

Apesar da maior frequência de patelas lateralizadas e retropés valgos aumentados entre os sujeitos com SPF, não houve associação significativa entre patela lateralizadas, aumento do valgo do retropé e aumento do ângulo $Q$ e a ocorrência da disfunção.

Houve uma predominância de patelas lateralizadas em ambos os grupos. Este achado está de acordo com outros estudos que avaliaram esta medida e encontraram que mesmo em indivíduos assintomáticos existe uma predominância de patelas lateralizadas (Powers et al., 1999; Herrington, 2008). Portanto, alguns autores concluem que sendo a lateralização da patela um achado comum na população assintomática, a orientação médio- 
lateral da patela deveria ser revista como fator de risco para a SPF assim como uma forma de avaliação clínica para a prescrição/ colocação de taping patelar (Powers et al., 1999; Wilson, 2007). No entanto, segundo McConnell (1996), não se deve considerar a posição mais comum como base para inferências sobre o alinhamento ideal da patela e sim a posição ótima. Neste sentido, esta autora recomenda que os fisioterapeutas deveriam continuar a aplicar o taping em patelas lateralizadas de sujeitos com SPF na busca de um alinhamento ideal da patela em relação ao fêmur, e conseqüentemente uma diminuição das forças compressivas e alívio da dor, apesar de encontrarmos com freqüência patelas lateralizadas nos indivíduos assintomáticos.

Não houve diferença significativa entre os grupos na quantidade de lateralização da patela. Este achado não concorda com um recente estudo que encontrou uma maior lateralização da patela em sujeitos com SPF. Este estudo, no entanto avaliou os sujeitos em $20^{\circ}$ de flexão do joelho em decúbito dorsal, enquanto o presente estudo avaliou os sujeitos em extensão (Herrington, 2008).

Segundo Herrington (2008), o trajeto em que a patela se move nos primeiros graus da flexão ainda não está bem estabelecido e a avaliação em $20^{\circ}$ de flexão deve ser vista com certa cautela, sendo necessários estudos que avaliem em outras angulações. Teoricamente, esperamos menos lateralização em $20^{\circ}$ do que em extensão completa, pelo mecanismo de travamento que ocorre no final da extensão, levando o fêmur à uma medialização em relação á tíbia. Este fato pode explicar porque as médias encontradas neste estudo são maiores do que aquelas encontradas no estudo que avaliou em $20^{\circ}$ de flexão. Além disto, Herrington (2008) utilizou uma amostra relativamente pequena $(n=12)$ exclusivamente composta por mulheres onde todos os sujeitos apresentavam patelas lateralizadas, limitando a generalização dos seus achados. 
Com relação à quantidade de medialização da patela, o GC apresentou maior medialização que o GSPF. Este achado sugere que os indivíduos que possuem maior medialização da patela com o quadríceps relaxado em supino, como foi avaliado neste estudo, teriam maiores chances de obter um posicionamento mais centralizado da patela durante a movimentação do joelho com a contração do quadríceps que fisiologicamente leva ao tracionamento lateral da patela. No entanto, é importante relembrar que esta maior medialização da patela aconteceu em apenas $26 \%$ dos indivíduos assintomáticos. Estudos com o quadríceps contraído em supino em várias angulações de flexão poderiam aprofundar esta discussão.

Quanto ao ângulo do retropé, não foi encontrada diferença entre as médias do GSPF e GC, sugerindo não haver relação entre a postura do retropé em posição ortostática e a ocorrência da SPF. Este achado concorda com alguns estudos que também não encontraram diferença entre a postura do retropé em ortostatismo e a ocorrência de SPF(Messier et al., 1991; Thomee et al., 1995; Livingston e Mandigo, 2003). No entanto, não está de acordo com o estudo que encontrou um aumento do valgo do retropé em ortoestatismo em sujeitos com SPF (Levinger e Gilleard, 2004). Com relação à distribuição de retropés varos, valgos e valgos aumentados, apesar de não ter sido encontrada associação significativa entre a distribuição dos retropés e a SPF, os sujeitos com SPF apresentaram maiores porcentagens de retropés valgos aumentados, enquanto o GC apresentou maiores porcentagens de retropés varos. Acredita-se que pela característica multifatorial da SPF, muitos fatores tendem a contribuir como fator de risco para esta disfunção. Neste sentido, pequenas contribuições quando somadas poderiam acarretar o surgimento da SPF, tornando-se difícil separar estas contribuições de forma isolada. 
No que diz respeito ao ângulo $Q$, não houve diferença entre as médias apresentadas pelos grupos. Apesar de alguns autores (Messier et al., 1991; Emami et al., 2007) terem encontrado relação entre o aumento do Ângulo $Q$ e a ocorrência de SPF, segundo a revisão de literatura organizada por Livingston (1998), não existem evidências científicas que sustentem a afirmação de que o ângulo $Q$ aumentado, de forma isolada, determine a ocorrência da SPF. Os resultados deste estudo confirmam esta constatação. Além disso, na distribuição dos dados, surpreendentemente os indivíduos com SPF mostraram maiores porcentagens de ângulos $Q$ considerados diminuídos e menores porcentagens de aumentados, embora esta distribuição não se mostrasse significativa.

Sabe-se que a medida do ângulo $Q$ pode ser influenciada pela posição em que os sujeitos adotam durante a avaliação. Este estudo avaliou ângulo $Q$ em ortostatismo para ambos os grupos, porque nesta posição onde há descarga de peso e o quadríceps está relativamente ativo se aproxima melhor das situações do cotidiano em que a articulação patelofemural sofre sobrecarga, diferente da avaliação em decúbito dorsal. Os pés dos sujeitos estavam paralelos e com a distância entre si padronizada o que diminui a possibilidade da comparação dos resultados do ângulo $Q$ entre os grupos ter sido influenciada pela falta de padronização das rotações dos membros inferiores (Sacco et al., 2007). Sendo assim, os resultados encontrados reforçam o questionamento da associação entre ângulo Q e a SPF.

Os resultados das medidas clínicas de alinhamento postural avaliadas neste estudo não confirmam a teoria de que o valgo aumentado do retropé, o ângulo $Q$ aumentado e a lateralização da patela estejam associados à SPF. Futuros estudos que verifiquem 0 alinhamento postural de sujeitos com SPF em situações mais desafiadoras, como por 
exemplo, em apoio unipodal, podem aprofundar a discussão sobre a associação do alinhamento postural dos membros inferiores e a ocorrência de SPF.

\subsection{Considerações finais do Experimento 1}

Não houve associação entre o alinhamento do retropé, e orientação médio-lateral da patela e a ocorrência da SPF. No entanto, os sujeitos com esta disfunção apresentaram maiores porcentagens não significativas de retropés valgos aumentados e patelas lateralizadas. Sendo a SPF uma disfunção de caráter multifatorial, é possível que pequenas contribuições de desalinhamento postural quando somadas, acarretem o surgimento da SPF, tornando-se difícil analisar estas contribuições de forma isolada.

No que diz respeito ao ângulo $Q$, além de não haver associação entre esta medida e a SPF, surpreendentemente os indivíduos com SPF mostraram maiores porcentagens de ângulos $Q$ considerados diminuídos e menores porcentagens de aumentados. Os resultados encontrados neste estudo questionam a associação entre o ângulo $Q$ aumentado e a SPF. 
Uma parte deste estudo foi apresentada no XI EMED Scientific Meeting em Dundee, Escócia em Julho de 2008 (ANEXO 4).

\subsection{Objetivo}

O segundo experimento objetivou investigar a distribuição da pressão plantar em indivíduos com e sem diagnóstico de SPF durante o descer escadas, e avaliar a dor dos sujeitos com essa disfunção antes e após a execução da tarefa proposta.

\subsection{Casuística e Métodos do Experimento 2}

Casuística

A amostra foi constituída por 74 adultos de ambos os sexos. O GC foi composto de 44 sujeitos, sendo 39 mulheres e 5 homens com idade média de $30 \pm 8$ anos, estatura de $165 \pm 8 \mathrm{~cm}$ e massa $59 \pm 960 \pm 11 \mathrm{~kg}$. O GSPF foi composto de 30 sujeitos, sendo 26 mulheres e 4 homens com idade média de $30 \pm 7$ anos, estatura de $165 \pm 9 \mathrm{~cm}$ e massa de $63 \pm 11 \mathrm{~kg}$. 0 GSPF apresentou mediana de 68 pontos na Escala Funcional do Joelho de Lysholm. Os grupos foram semelhantes quanto à porcentagem de indivíduos fisicamente ativos ( $G C=44,2 \%, G S P F=41,4 \% ; p=0,812)$, tempo de prática em anos (GC=5 \pm 6 anos, GSPF= 3 \pm 4anos; $p=0,221)$, freqüência em dias por semana $(G C=3 \pm 1$ dias/sem, 
$\mathrm{GSPF}=3 \pm 1$ dias/sem; $p=0,703)$ e duração em minutos $(\mathrm{GC}=77 \pm 38 \mathrm{~min}, \mathrm{GSPF}=67 \pm 2 \mathrm{~min}$, $p=0,794)$ da atividade física praticada.

Material e Métodos

A avaliação da distribuição da pressão plantar foi realizada utilizando-se o Sistema Pedar X (Novel, Munique, Alemanha) a uma freqüência de amostragem de $100 \mathrm{~Hz}$. Este equipamento é composto de palmilhas capacitivas com dois $\mathrm{mm}$ de espessura, composta de 99 sensores de pressão, distribuídos homogeneamente, com resolução dependente do tamanho da palmilha, aproximadamente um sensor $/ \mathrm{cm}^{2}$. As palmilhas são conectadas a um condicionador colocado dentro de uma mochila justaposta às costas do indivíduo e a transmissão dos dados é feita via Bluetooth para o computador. O sistema mochila, condicionador tinha uma massa de $1,5 \mathrm{~kg}$. Os sujeitos usaram as palmilhas dentro de meias antiderrapantes justapostas aos pés e fixadas por fitas de velcro em volta dos tornozelos (Burnfield et al., 2004). Segundo Willems et al (2006) apesar das atividades físicas ou atividades de vida diária serem realizadas na maioria das vezes com os indivíduos calçados, avaliar na condição calçada pode mascarar padrões biomecânicos intrínsecos dos pés. Como o objetivo deste estudo foi comparar os padrões biomecânicos intrínsecos dos pés entre os grupos, entendemos que a condição descalça foi mais adequada aos nossos propósitos.

Os indivíduos foram instruídos a descer os cinco degraus de uma escada construída conforme as recomendações da Associação Brasileira de Normas Técnicas (ABNT) sem apoiar no corrimão. As dimensões dos degraus eram: $60 \mathrm{~cm}$ de largura por $32 \mathrm{~cm}$ de comprimento e $16 \mathrm{~cm}$ de altura (ABNT, 2004) (figura 12). 
Os indivíduos subiam os cinco degraus da escada todas as vezes antes de descê-los para serem avaliados. A cadência foi controlada por um metrônomo em 96 bpm com o objetivo de minimizar a interferência da velocidade de execução da tarefa nos resultados assim como assegurar a reprodutibilidade dos resultados usando o sistema Pedar (Kernozek e Zimmer, 2000).

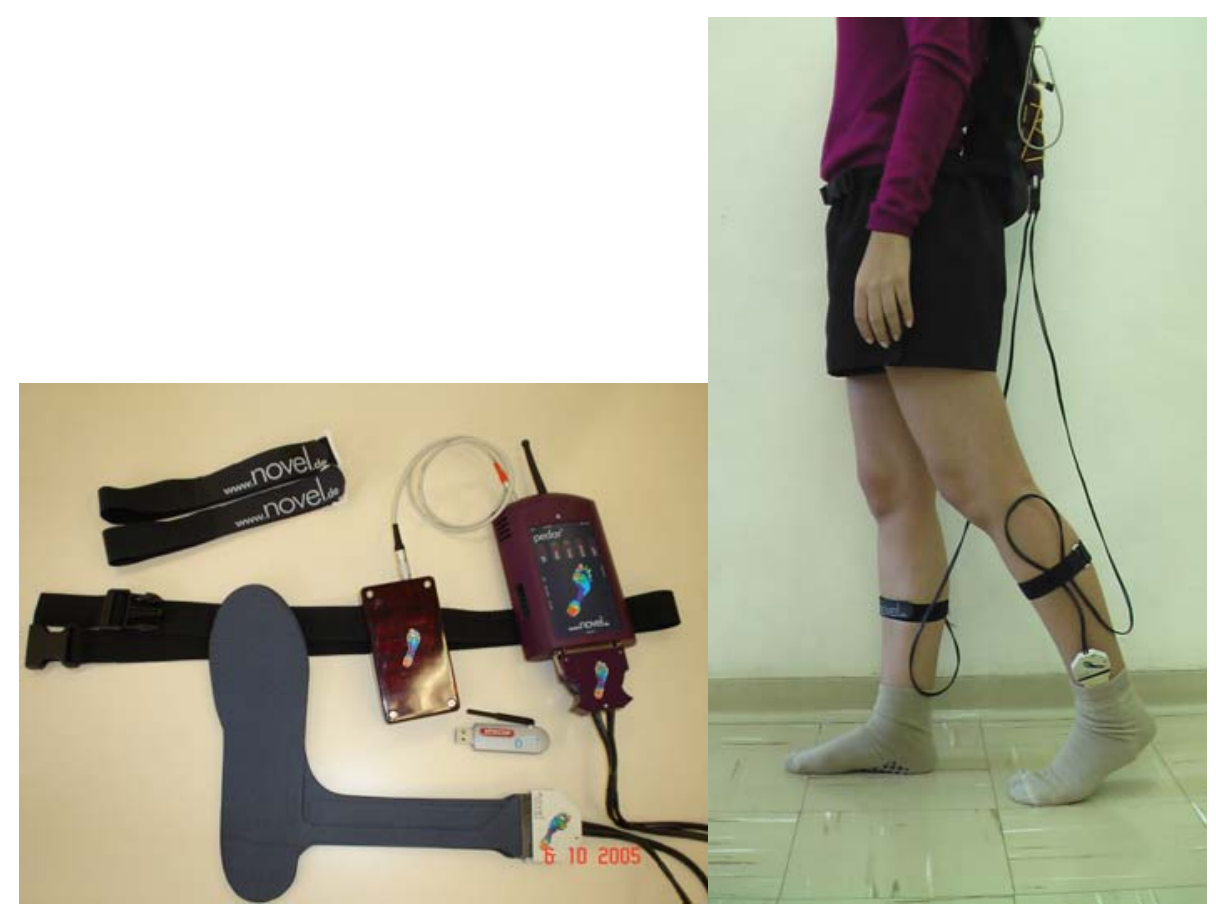

Figura 11. Pedar X System, bateria, condicionador (box) com cabos para conexão nas palmilhas, fitas para fixação do equipamento no sujeito e dispositivo bluetooth.Situação exemplar do sujeito com as palmilhas colocadas dentro de meias antiderrapantes, usando a mochila nas costas contendo o condicionador do Pedar X. 


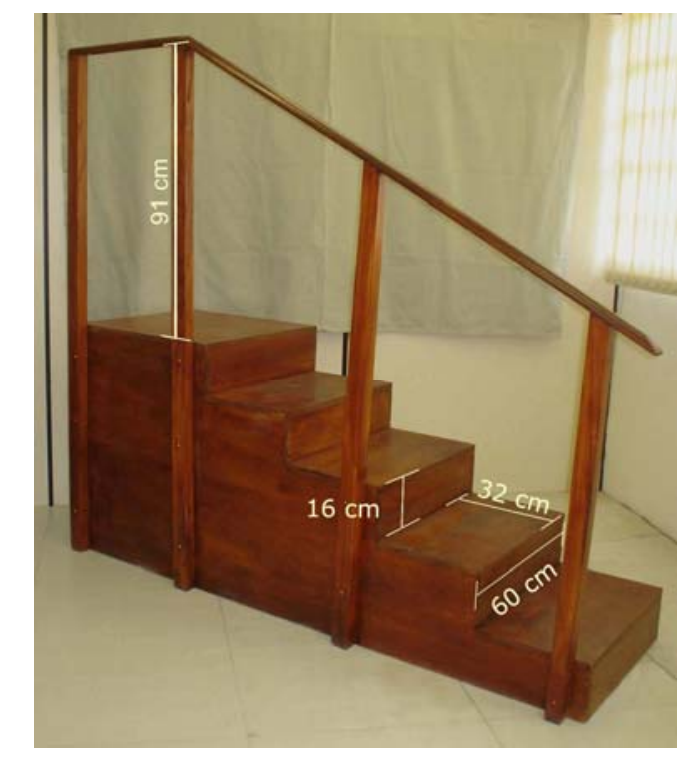

Figura 12. Escada construída com dimensões conforme as normas da ABNT.

Os sujeitos passaram por um a habituação ao ambiente de coleta e aos instrumentos, com o objetivo de diminuir o efeito retroativo do equipamento e ambiente nas variáveis mensuradas. Após a habituação e antes das tentativas coletadas pediu-se para que os sujeitos levantassem um pé de cada vez do chão para que o valor zero de pressão fosse tarado. Após a habituação e calibração do zero de pressão, foram coletados uma média de 8 apoios por sujeito. Este número de apoios coletados permite aumentar a reprodutibilidade dos dados, fundamentalmente devido o elevado coeficiente de variação que ocorre na análise da distribuição plantar (Sacco e Amadio, 2000).

Foram considerados válidos dois dos apoios centrais, que correspondiam ao membro inferior a ser avaliado. Por exemplo, se o membro inferior avaliado fosse o direito, o sujeito começava a descer com o esquerdo para que o membro inferior direito fizesse apoio no terceiro e quinto degraus da escada. Assim, eliminou-se a fase de aceleração inicial e desaceleração final da tarefa, assegurando uma característica mais homogênea das fases de apoio analisadas. 
As variáveis analisadas foram: área de contato, pico de pressão e integral da pressão. A variável área de contato representa a área correspondente aos sensores ativados (pressionados) sendo expressa em $\mathrm{cm}^{2}$. O pico de pressão representa o valor máximo de pressão atingido entre todos os sensores na área avaliada e sua unidade de medida é $\mathrm{kPa}$. $\mathrm{A}$ integral da pressão, por sua vez, representa o impulso local, ou seja, o tempo que durou o pico de pressão na área avaliada, sendo medida em kPa por segundo.

As variáveis área de contato $\left(\mathrm{cm}^{2}\right)$, o pico de pressão $(\mathrm{kPa})$ e a integral da pressão(kPa.s) foram avaliadas em 6 áreas plantares que se ajustavam via software proporcionalmente à largura e comprimento do pé de cada sujeito. A superfície plantar foi inicialmente divida em 3 grandes regiões em relação ao comprimento do pé:retropé (30\%), médio-pé(30\%), e antepé (40\%), seguindo o esquema estabelecido por Cavanagh e Ulbrecht (1994). O retropé e o antepé foram subdivididos em relação à largura correspondente a cada uma destas áreas, respectivamente, em: retropé medial (30\%),retropé central (40\%) e retropé lateral (30\%); antepé medial (55\%) e antepé lateral (45\%) (figura13).

Avaliou-se a intensidade da dor nos indivíduos com SPF por meio da Escala Visual Analógica de Dor (EVA) (Williamson e Hoggart, 2005) em dois momentos: (1) assim que os indivíduos chegavam ao laboratório durante a avaliação inicial, e (2) após a habituação e coleta das tentativas válidas da tarefa descer escadas. A EVA é um instrumento validado e confiável (ICC entre 0,97 e 0,99) para a avaliação da intensidade da dor (Williamson e Hoggart, 2005) que tem sido usado na avaliação clínica da SPF (Natri et al., 1998). 


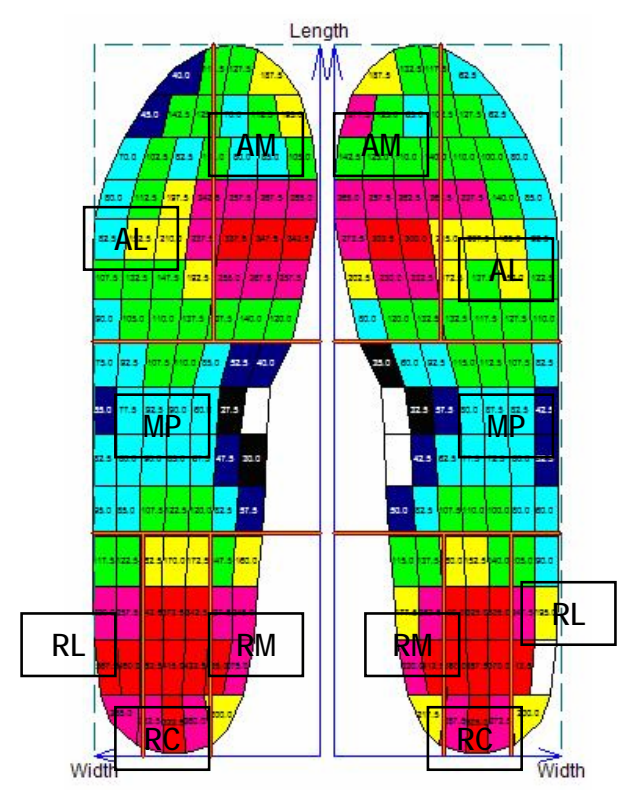

Figura 13. Representação da divisão da superfície plantar em 6 áreas para a análise da distribuição da pressão plantar : retropé medial $(R M)$, retropé central $(R C)$,retropé lateral $(R L)$, médio-pé (MP), antepé medial (AM) e antepé lateral (AM).

Análise Estatística

O tratamento estatístico foi realizado no Statistica v.7(Statsoft Inc.) e o tratamento matemático das variáveis da distribuição da pressão plantar foi realizado no programa Novel Multiprojects. As variáveis de distribuição da pressão plantar seguiram uma distribuição normal pelo teste de Shapiro-Wilk e homogeneidade de variância pelo teste de Levene. No GSPF foi selecionado o pé que correspondia ao joelho com dor (sujeitos com dor unilateral) e o pé que correspondia ao joelho com maior dor (sujeitos com dor bilateral) totalizando-se 30 pés. No GC o pé analisado foi escolhido aleatoriamente, considerando a habilidade locomotora avaliada simétrica em sua natureza (Winter, 1991) totalizando-se 44 pés. Para as variáveis de distribuição da pressão plantar foram utilizadas 3 ANOVAs dois fatores (2X6) sendo as 6 áreas plantares medidas repetidas, seguidas do post-hoc de Newman-Keuls. A 
EVA não seguiu uma distribuição normal, portanto, utilizou-se o teste Wilcoxon para sua comparação pré e pós avaliação. O nível de significância adotado foi $\alpha=5 \%$.

\subsection{Resultados do Experimento 2}

A tabela 2 mostra os resultados da área de contato em cada uma das seis áreas plantares para os dois grupos. Houve efeito de interação grupo e áreas plantares para a área de contato $(F=3,343 ; p=0,042)$. A área de contato foi significativamente maior no GSPF em relação ao GC no retropé medial e no médio-pé.

Tabela 2. Médias, desvios padrão e valores do $p$ do teste post hoc da àrea de contato $\left(\mathrm{cm}^{2}\right)$ nas 6 áreas plantares do grupo controle (GC) e grupo síndrome da dor patelofemural (GSPF) durante 0 descer escadas.

\begin{tabular}{lccc}
\hline \multicolumn{1}{c}{ Áreas Plantares } & GC (cm $\left.{ }^{2}\right)$ & GSPF $\left(\mathbf{c m}^{2}\right)$ & $\mathbf{p}^{\dagger}$ \\
\hline Retropé Medial & $10,5 \pm 3,7$ & $12,3 \pm 3,8$ & $0,019^{*}$ \\
Retropé Central & $16,2 \pm 2,3$ & $16,3 \pm 2,4$ & 0,858 \\
Retropé Lateral & $5,5 \pm 3,5$ & $5,1 \pm 3,6$ & 0,489 \\
Médio-pé & $22.3 \pm 5,4$ & $25,9 \pm 5,4$ & $0,000^{*}$ \\
Antepé Medial & $35,3 \pm 3,8$ & $36,5 \pm 1$ & 0,154 \\
Antepé Lateral & $23,7 \pm 3,1$ & $24,9 \pm 2,2$ & 0,116 \\
\hline
\end{tabular}

†Post hoc de Newman-Keuls ${ }^{*} p \leq 0,05$

Os resultados para o pico de pressão são apresentados na figura 14. Não houve efeito de interação entre os grupos e áreas plantares $(F=1,216 ; p=0,299)$. No entanto observou-se efeito significante de grupo ( $F=3,342 ; p=0,039)$ onde o GSPF apresentou menores picos de pressão. A tabela 3 apresenta os resultados para a variável integral da pressão. Não houve diferença entre os grupos e áreas plantares para esta variável $(F=1.166$; $p=0.324)$. 


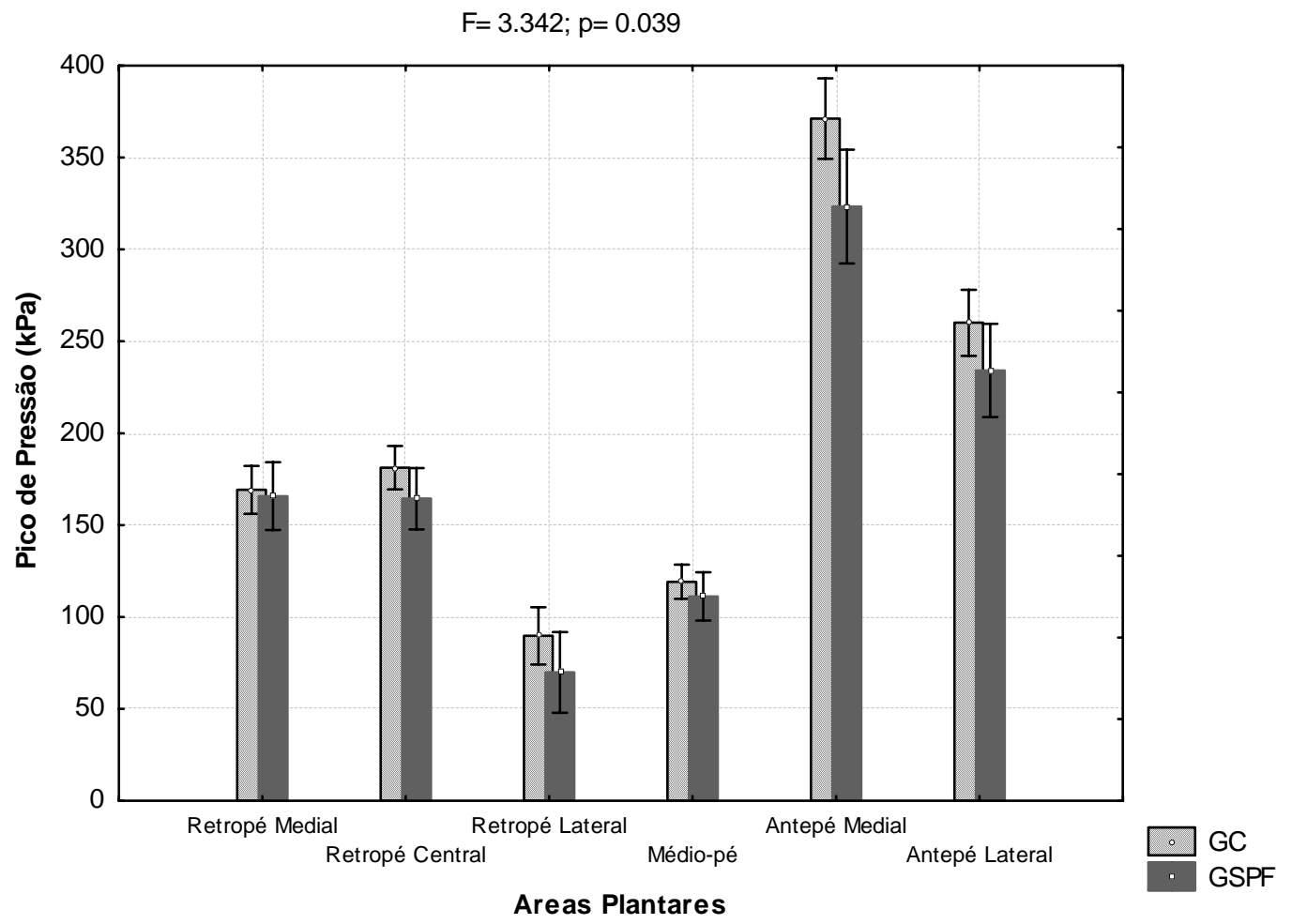

Figura 14. Médias e desvios padrão do pico de pressão $(\mathrm{kPa})$ nas 6 áreas plantares do grupo controle (GC) e grupo síndrome da dor patelofemural (GSPF) durante o descer escadas.

Tabela 3. Médias e desvios padrão da integral da pressão (kPa.s) nas 6 áreas plantares do grupo controle (GC) e grupo síndrome da dor patelofemural (GSPF) durante 0 descer escadas.

\begin{tabular}{lcc}
\hline \multicolumn{1}{c}{ Áreas Plantares } & GC (kPa.s) & GSPF(kPa.s) \\
\hline Retropé Medial & $38,3 \pm 17,0$ & $41,86 \pm 19,0$ \\
Retropé Central & $45,3 \pm 16,9$ & $44,72 \pm 22,2$ \\
Retropé Lateral & $26,3 \pm 16,5$ & $25,68 \pm 25,6$ \\
Médio-pé & $33,4 \pm 13,9$ & $34,16 \pm 12,8$ \\
Antepé Medial & $145,9 \pm 32,8$ & $135,22 \pm 33,3$ \\
Antepé Lateral & $109,7 \pm 34,9$ & $104,24 \pm 31,8$ \\
\hline
\end{tabular}

A comparação da dor no joelho por meio da EVA no GSPF antes e depois do protocolo, revelou um aumento da intensidade da dor de $9 \%$ após a realização do protocolo de coleta $(2,5 \pm 2,3 \mathrm{~cm})$ em relação à intensidade da dor assinalada antes do protocolo 
$(1,6 \pm 2,3 \mathrm{~cm})(p=0,003)$. 0 grupo controle apresentou dor igual a $0,0 \mathrm{~cm}$ e após a realização do protocolo manteve este mesmo índice de dor.

\subsection{Discussão do Experimento 2}

O objetivo deste estudo foi investigar a distribuição da pressão plantar em indivíduos com e sem diagnóstico de SPF na fase de apoio do descer escadas, e avaliar a dor dos sujeitos com SPF antes e após a realização da tarefa motora.

Os principais resultados apontam para uma diferente geometria de colocação do pé no solo durante o descer escadas no GSPF. Sujeitos com a SPF aumentam sua área de contato nas regiões mais mediais de retropé e médio-pé, sobrecarregam com menos intensidade o pé ao descer escadas e referem aumento de dor após a realização da tarefa.

O aumento da área de contato nas regiões correspondentes ao retropé medial e ao médio-pé nos indivíduos com SPF sugere uma maior excursão do pé medialmente. Uma diminuição da área de contato no médio-pé foi observada na marcha de sujeitos usando calçados que restringiam o movimento médio - lateral do pé em comparação com a marcha descalça, indicando uma provável associação da área de contato com a quantidade de pronação do pé (Teyhen et al. 2006). Os resultados encontrados no presente estudo, corroboram esta associação em sujeitos com SPF.

No entanto, Thijs et al (2007), em um estudo prospectivo, avaliaram a pressão plantar na marcha de militares e encontraram um apoio mais lateralizado no contato inicial assim como no rolamento do pé durante o apoio em sujeitos que desenvolveram a SPF. Segundo estes autores, os indivíduos avaliados eram submetidos a uma alta intensidade e freqüência de exercícios com pouco tempo de recuperação. Portanto, é preciso ter cautela na 
generalização dos resultados deste estudo de Thijs et al. (2007) para indivíduos que não possuem estas características intensas de atividade física como no caso de militares. Além disso, o presente estudo avaliou uma tarefa de maior demanda mecânica e muscular que pode revelar movimentos compensatórios que não são observados na marcha no plano.

Houve efeito de grupo e, portanto, efeito da SPF no pico de pressão plantar. Nesse sentido, sujeitos com SPF apresentaram menores picos de pressão no descer escadas, sugerindo que estes indivíduos realizam esta tarefa motora de forma mais cautelosa com menores cargas em relação aos indivíduos assintomáticos.

Powers et al. (1999) encontraram menores forças de reação do solo no andar em sujeitos com SPF na marcha e Brechter e Powers (2002)observaram menores momentos extensores do joelho destes sujeitos no descer escadas. Segundo estes autores, esta estratégia relaciona-se a uma tentativa de diminuição da força de reação na articulação patelofemural objetivando reduzir sobrecarga e consequentemente dor. Nossos resultados de pressão plantar parecem corroborar estas afirmações.

Apesar dos menores picos de pressão encontrados nos sujeitos com SPF, a integral da pressão foi semelhante entre os grupos. Como a integral da pressão caracteriza-se por ser o impulso do pico de pressão no tempo, sugere-se que o tempo de contato pode estar aumentado no grupo com SPF. Isto parece ser particularmente verdade para o retropé medial e médio-pé onde os valores médios da integral da pressão são maiores para o grupo com SPF. Estes resultados sugerem que os indivíduos com SPF permanecem sobrecarregando a superfície plantar de maneira distinta, mesmo que de forma não significativa, e corroboram a hipótese de apoio medializado, encontrados no aumento da área de contato para estas duas regiões nos indivíduos com SPF. 
É importante ressaltar que a cadência do descer escadas foi controlada no presente estudo, fato que afasta a possibilidade de os menores picos de pressão observados no GSPF serem decorrentes de uma velocidade de execução da tarefa reduzida em relação aos indivíduos assintomáticos. Nesse sentido, os menores picos de pressão encontrados podem estar relacionados com o aumento da dor nos sujeitos com SPF após o descer escadas.

Levinger e Gilleard (2007) discutiram a dificuldade em se diferenciar um padrão característico do indivíduo de uma estratégia de proteção para evitar o aumento da sintomatologia em sujeitos com SPF. Para tanto, neste estudo foi avaliada a intensidade da dor antes e depois do descer escadas com o objetivo de melhorar o entendimento da relação entre os resultados da distribuição da pressão plantar e a dor. Desta forma, sugere-se que a coexistência de menores picos de pressão no descer escadas e aumento da intensidade da dor após a realização dessa tarefa, confirma uma estratégia de proteção adotada pelos sujeitos com SPF.

Encontrar a conseqüência de uma estratégia de proteção na distribuição da pressão plantar em sujeitos com SPF indica que este método pode ser utilizado para avaliar os resultados funcionais de um tratamento realizado para esta disfunção, assim como tem sido utilizado para outras disfunções musculoesqueléticas dos membros inferiores (Mittlmeier et al., 1999)

\subsection{Considerações finais do Experimento 2}

Sujeitos com SPF apresentam um apoio medialmente direcionado no retropé e médio-pé durante o descer escadas. Além disto, apresentam menor sobrecarga plantar no pé como um todo caracterizando um padrão mais cauteloso de descer escadas. Estes achados 
sugerem que a SPF está relacionada ao apoio do pé no solo em uma posição mais evertida, particularmente no retropé, e de menor sobrecarga em tarefas mais desafiadoras em termos de demanda mecânica e muscular, como o descer escadas. Estas menores sobrecargas plantares estão provavelmente associadas ao aumento significativo da dor que os indivíduos relataram após a tarefa, evidenciando um descer escadas mais cauteloso na tentativa de não exacerbar a dor que descer escadas provoca. 


\section{EXPERIMENTO 3}

Parte deste estudo foi apresentada no XI EMED Scientific Meeting em Dundee, Escócia em Julho de 2008 (ANEXO 5).

\subsection{Objetivo}

Este estudo teve como objetivo avaliar a influência da SPF na distribuição da pressão plantar durante o rolamento do pé na fase de apoio da marcha em três sub-fases: no contato inicial, médio-apoio e na propulsão.

\subsection{Casuística e Métodos do Experimento 3}

Casuística

A amostra foi constituída por 57 adultos de ambos os sexos. O GC foi composto de 35 sujeitos, sendo 32 mulheres e 3 homens com idade média de $29 \pm 7$ anos, estatura de $164 \pm 8 \mathrm{~cm}$ e massa $60 \pm 11 \mathrm{~kg}$. O GSPF foi composto de 22 sujeitos, sendo 20 mulheres e 2 homens com idade média de $30 \pm 7$ anos, estatura de $165 \pm 9 \mathrm{~cm}$ e massa de $63 \pm 12 \mathrm{~kg}$. Os indivíduos do GSPF apresentavam média e desvio padrão na EVA de $1,7 \pm 2,3 \mathrm{~cm}$, e mediana da pontuação na Escala Funcional do Joelho de Lysholm de 70 pontos.

Com relação à porcentagem de indivíduos fisicamente ativos (GC=51,3\%; $\mathrm{GSPF}=48,7 \% ; p=0,422)$, tempo de prática em anos $(G C=5 \pm 5$ anos; GSPF $=5 \pm 2$ anos; $p=$ 
0,330), freqüência em dias/semana ( $G C=3 \pm 1$ dias/sem; $G S P F=2 \pm 1$ dias $/$ sem; $p=0,246)$ e duração da atividade em minutos $(G C=85 \pm 30 \mathrm{~min} ; \mathrm{GSPF}=68 \pm 22 \mathrm{~min} ; \mathrm{p}=0,534)$ os grupos apresentaram-se semelhantes.

Material e Métodos

A distribuição da pressão plantar foi avaliada durante a marcha descalça utilizando-se os dados provenientes das palmilhas capacitivas (Pedar X System, Novel, Munique, Alemanha) - já descritas nos métodos do experimento 2 - sincronizados aos dados de flexão e extensão do tornozelo adquiridos por meio de um eletrogoniômetro biaxial de tornozelo (modelo SG110/A, Biometrics,Gwent,Inglaterra). O eletrogoniômetro biaxial era composto de dois blocos: um bloco móvel (telescópico) e um bloco fixo unidos por uma mola instrumentada com células de carga (strain gauges) (figura 15).

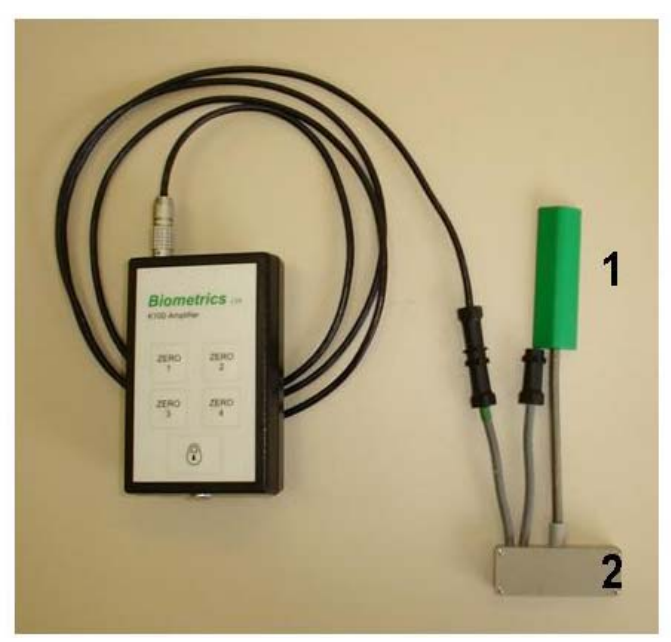

Figura 15. Eletrogoniômetro biaxial de tornozelo (1= bloco móvel, 2 = bloco fixo).

O bloco fixo foi posicionado paralelo ao maior eixo do pé, abaixo do maléolo lateral, enquanto o bloco móvel foi posicionado alinhado ao maior eixo da perna. A mola constituída por células de carga foi mantida tensa e seu centro coincidia com o eixo articular do tornozelo 
(sobre o maléolo lateral) (figura 16). 0 eletrogoniômetro foi calibrado com o indivíduo em posição ortostática relaxada, solicitando-se que o indivíduo distribuísse o peso corporal igualmente entre os dois pés. $\mathrm{O}$ valor adquirido neste momento foi considerado o zero para 0 eletrogoniômetro. Por convenção da literatura (Winter, 1991), o movimento anterior do pé foi considerado flexão (valores positivos) e o movimento posterior do pé foi considerado extensão (valores negativos).

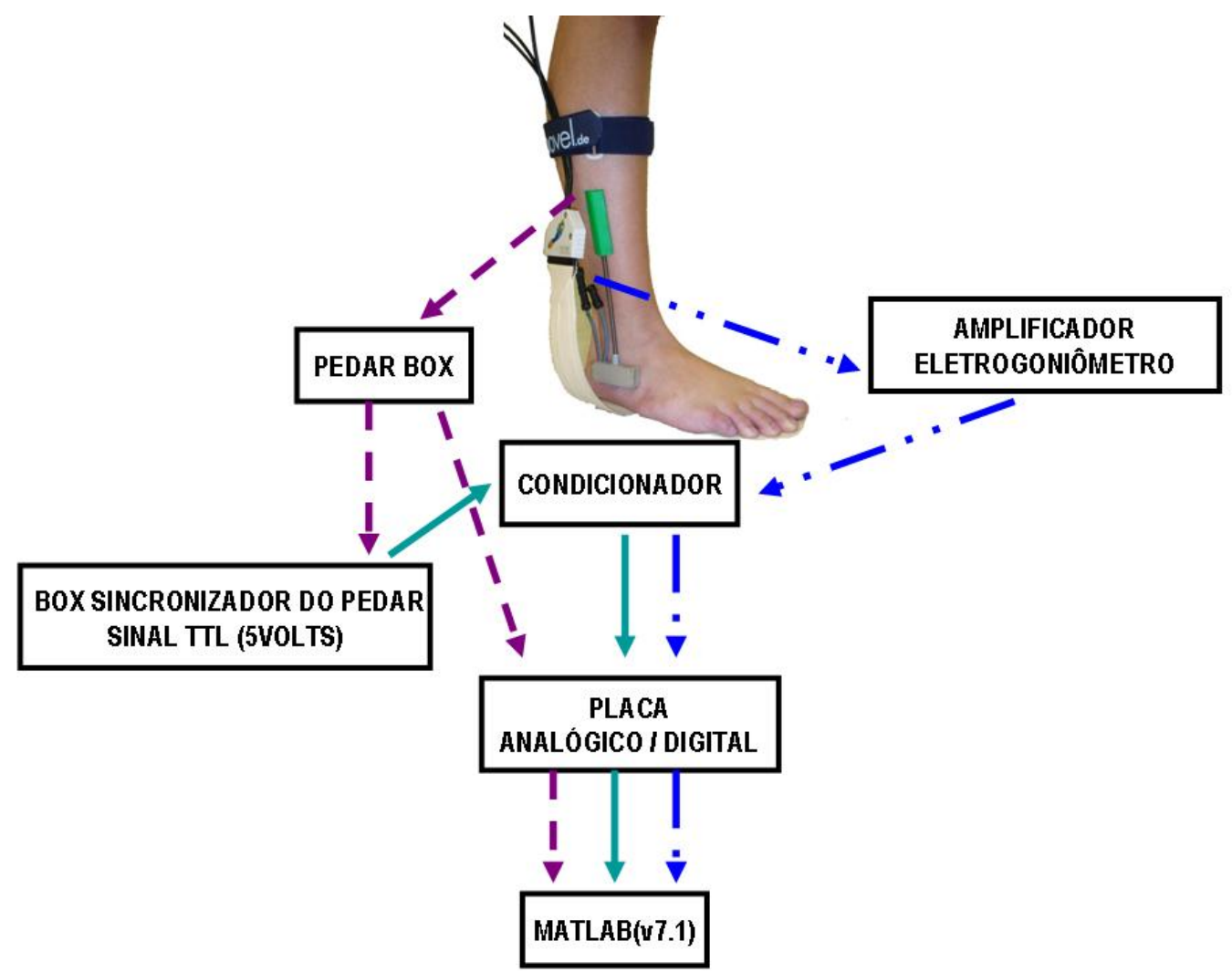

Figura 16. Esquema da sincronização entre os dados de distribuição da pressão plantar (Pedar X System) e variação angular de flexão e extensão do tornozelo (eletrogoniômetro) por meio do box sincronizador do pedar (sinal TTL).

As aquisições do sistema Pedar $\mathrm{X}$ e Eletrogoniômetro foram feitas a uma frequência de amostragem de $100 \mathrm{~Hz}$ e sincronizados por um sinal TTL (5 volts) proveniente do box sincronizador do Pedar $\mathrm{X}$ System que era interrompido no momento em que o pé tocava 0 solo (pressão $>20 \mathrm{kPa}$ ) e voltava a ser emitido assim que o pé se desprendia do solo 
(pressão < 20kPa). Uma placa analógico/digital (digital/analógica) de 12-bits foi usada para processar os dados provenientes dos dois instrumentos (figura 16).

Antes da aquisição dos dados, os sujeitos foram instruídos a caminhar livremente pela passarela até se sentirem confortáveis, como forma de habituação ao ambiente do laboratório e aos equipamentos. Após a habituação, foram coletados aproximadamente 15 passos por indivíduo. Um metrônomo digital foi usado para controlar a cadência entre $96 \mathrm{e}$ 112 passos por minuto (média $\pm d p, G C=108 \pm 3 p p m ; G S P F=G C=107 \pm 3 p p m ; p=0,871$ ), com o objetivo de minimizar a interferência da cadência da marcha nos resultados obtidos entre os sujeitos e tentativas.

O Pedar X System tem a vantagem de adquirir vários passos ao mesmo tempo, tornando-se mais confiável na medida em que os dados de pressão adquiridos provém da média de vários passos. Apesar da marcha descalça ser usualmente avaliada por meio de uma plataforma de pressão como o EMED (Novel, Munique, Alemanha), principalmente por sua maior resolução, os resultados deste estudo foram influenciados minimamente por este fator, pois as áreas plantares eram grandes o bastante para serem adquiridas com a resolução espacial do Pedar X System.

A área de contato $\left(\mathrm{cm}^{2}\right)$, o pico de pressão $(\mathrm{kPa})$ e a integral da pressão(kPa.s) foram avaliadas em 6 áreas plantares que se ajustavam via software proporcionalmente à largura e comprimento do pé de cada sujeito. A superfície plantar foi inicialmente divida em 3 grandes regiões em relação ao comprimento do pé: retropé (30\% do comprimento do pé), médio-pé (30\% do comprimento do pé), e antepé e dedos (40\% do comprimento do pé), seguindo 0 esquema estabelecido por Cavanagh and Ulbrecht (1994). O retropé e o antepé foram subdivididos em relação à largura correspondente a cada uma destas áreas, respectivamente, em: retropé medial (30\% da largura do retropé), retropé central (40\% da 
largura do retropé) e retropé lateral (30\% da largura do retropé); antepé medial (55\% da largura do antepé) e antepé lateral (45\% da largura do antepé) (figura 13).

Análise dos Dados

Uma rotina matemática foi escrita em ambiente MATLAB (versão 7.1) com o objetivo calcular as variáveis da distribuição da pressão plantar nas 6 áreas plantares e em três fases do apoio da marcha. Foi considerada a fase do contato inicial o momento entre o primeiro contato do pé com o solo e a deflexão da curva de extensão para flexão do tornozelo (figura 17, entre A-B). A fase de médio-apoio foi considerada o momento entre a deflexão da curva de extensão para flexão do tornozelo no aplainamento do pé e o pico de flexão do tornozelo (figura 17, entre B-C). A fase de propulsão foi considerada do momento entre o pico de flexão do tornozelo e o desprendimento do pé com o solo (figura 17, entre C-D).

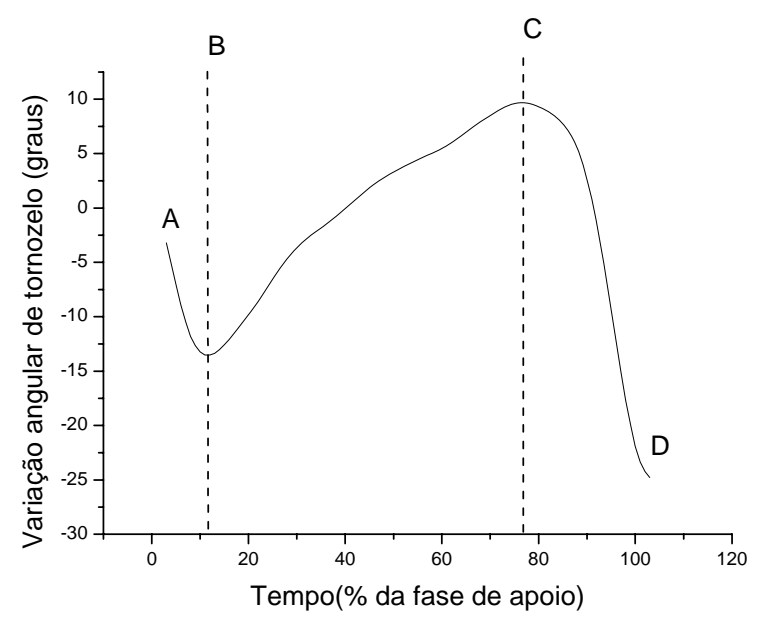

Figura 17. Representação da divisão das fases do apoio da marcha a partir da variação angular do tornozelo, sendo flexão (valores positivos) e extensão (valores negativos). $O$ contato inicial está entre $A-B, 0$ médio-apoio entre $B-C$ e a propulsão entre C-D. 
As comparações estatísticas entre os grupos das variáveis da pressão plantar durante as três fases do apoio do andar nas seis áreas plantares, foram realizadas no Statistica v.7 software (Statsoft Inc.). As variáveis da distribuição da pressão plantar seguiram uma distribuição normal pelo teste de Shapiro-Wilk e homogeneidade de variância pelo Teste de Levene. Os membros inferiores avaliados no grupo com SPF foram: o membro inferior que apresentava dor (disfunções unilaterais) e o membro inferior apresentava maior dor (disfunções bilaterais), totalizando 22 pés. 0 membro inferior avaliado no grupo controle foi selecionado por sorteio totalizando 35 pés. Os grupos foram comparados utilizando-se 4 ANOVAs 3-fatores (3X6), onde as fases(3) e as áreas plantares(6) foram consideradas medidas repetidas, seguidas do post-hoc de Newman-Keuls . O nível de significância adotado foi de 0,05. Valores de nível de significância entre 0,05 e 0,1 foram considerados marginalmente significativos.

\subsection{Resultados do Experimento 3}

A tabela 4 mostra as médias e desvios padrão do GC e GSPF para a área de contato e pico de pressão nas 6 áreas plantares durante as três fases do apoio do andar, assim como os valores do $p$ do post-hoc de newman-keuls na comparação entre os grupos.

Os grupos foram diferentes com relação à área de contato $(F=2,242, p=0,014)$. GSPF apresentou maior área de contato no retropé medial e central durante o contato inicial, maior área de contato no antepé lateral e medial (marginalmente significativa) durante 0 médio-apoio, e um aumento da área de contato no antepé lateral (marginalmente significativa) durante a propulsão. Os resultados do teste ANOVA mostraram que os grupos não foram diferentes com relação ao pico de pressão ( $F=0,831, p=0,598)$. No entanto, no post 
hoc de Newman-Keuls, o GSPF apresentou menor pico de pressão no antepé medial durante a propulsão. Os grupos não foram diferentes com relação à integral da pressão ( $F=0,352$, $p=0,958)$.

A figura 3 mostra as médias da integral da pressão nas 6 áreas plantares durante contato inicial, médio-apoio e propulsão da fase de apoio da marcha entre os grupos controle (GC) e síndrome da dor patelofemural (GSPF) .

Tabela 4. Médias, desvios padrão e valores do $p$ do post hoc de newman-keuls da área de contato $\left(\mathrm{cm}^{2}\right)$ e pico de pressão $(\mathrm{kPa})$ nas 6 áreas plantares durante 0 contato inicial, médio-apoio e propulsão do apoio da marcha entre os grupos controle (GC) e síndrome da dor patelofemural (GSPF)

\begin{tabular}{|c|c|c|c|c|c|c|c|}
\hline \multirow{2}{*}{\multicolumn{2}{|c|}{ Fases do Apoio Áreas Plantares }} & \multicolumn{3}{|c|}{ Área de Contato $\left(\mathrm{cm}^{2}\right)$} & \multicolumn{3}{|c|}{ Pico de Pressão (kPa.s) } \\
\hline & & $G C_{(n=35)}$ & GSPF (n=22) & $\mathbf{p}^{\varepsilon}$ & $\mathrm{GC}_{(\mathrm{n}=35)}$ & GSPF (n=22) & $\mathrm{p}^{\varepsilon}$ \\
\hline \multirow{6}{*}{ Contato Inicial } & Retropé Medial & $4,4 \pm 4,7$ & $6,5 \pm 3,2$ & $0,004^{*}$ & $151,5 \pm 109,3$ & $158,2 \pm 94,3$ & 0,517 \\
\hline & Retropé Central & $7,8 \pm 3$ & $10,4 \pm 1,9$ & $0,002^{*}$ & $180 \pm 89,9$ & $186,3 \pm 42,9$ & 0,829 \\
\hline & Retropé Lateral & $2,4 \pm 1,7$ & $2,2 \pm 2,3$ & 0,113 & $213,2 \pm 53,2$ & $200 \pm 41,9$ & 0,637 \\
\hline & Médio-pé & $0,1 \pm 0,4$ & $0,1 \pm 0,2$ & 0,910 & $1,7 \pm 4$ & $1,5 \pm 2,7$ & 0,984 \\
\hline & Antepé Medial & $0,3 \pm 0,4$ & $0,6 \pm 0,5$ & 0,966 & $4,6 \pm 4,3$ & $6,7 \pm 4,8$ & 0,868 \\
\hline & Antepé Lateral & $0,5 \pm 0,7$ & $0,5 \pm 0,6$ & 0,958 & $5,3 \pm 5,6$ & $5,4 \pm 5,3$ & 0,997 \\
\hline \multirow{6}{*}{ Médio-Apoio } & Retropé Medial & $8,3 \pm 3,9$ & $9,7 \pm 3,6$ & 0,113 & $8,3 \pm 3,9$ & $9,7 \pm 3,6$ & 0,985 \\
\hline & Retropé Central & $14 \pm 2,8$ & $14,9 \pm 2,1$ & 0,180 & $14 \pm 2,8$ & $14,9 \pm 2,1$ & 0,228 \\
\hline & Retropé Lateral & $4,9 \pm 2,9$ & $3,6 \pm 2,9$ & 0,210 & $4,9 \pm 2,9$ & $3,6 \pm 2,9$ & 0,884 \\
\hline & Médio-pé & $8,6 \pm 4,8$ & $9,4 \pm 4,4$ & 0,204 & $46,9 \pm 27,8$ & $56,7 \pm 25,9$ & 0,369 \\
\hline & Antepé Medial & $10,9 \pm 3,4$ & $12,1 \pm 4$ & $0,072 \S$ & $66,9 \pm 23,7$ & $76,3 \pm 29,3$ & 0,826 \\
\hline & Antepé Lateral & $10,8 \pm 3,2$ & $12,9 \pm 1,9$ & $0,005^{\star}$ & $70,5 \pm 27,6$ & $82,4 \pm 25,8$ & 0,695 \\
\hline \multirow{6}{*}{ Propulsão } & Retropé Medial & $1,6 \pm 1,4$ & $2,1 \pm 1,5$ & 0,536 & $19,1 \pm 16,6$ & $20 \pm 15,7$ & 0,995 \\
\hline & Retropé Central & $2,6 \pm 2,3$ & $3 \pm 1,9$ & 0,572 & $2,6 \pm 2,3$ & $3 \pm 1,9$ & 0,988 \\
\hline & Retropé Lateral & $0,3 \pm 0,8$ & $0,3 \pm 0,4$ & 0,849 & $0,3 \pm 0,8$ & $0,3 \pm 0,4$ & 0,998 \\
\hline & Médio-pé & $4,3 \pm 2,7$ & $4,1 \pm 2,6$ & 0,799 & $32,8 \pm 27,8$ & $31 \pm 23,9$ & 0,868 \\
\hline & Antepé Medial & $25,2 \pm 3,9$ & $25,5 \pm 2,5$ & 0,651 & $253,6 \pm 43,6$ & $230,5 \pm 46,4$ & $0,033^{*}$ \\
\hline & Antepé Lateral & $15,7 \pm 3,3$ & $16,8 \pm 2,7$ & $0,079 \S$ & $192 \pm 47,7$ & $193,8 \pm 46,6$ & 0,887 \\
\hline
\end{tabular}

£Post hoc de Newman-Keuls * $p \leq 0,05 \S p \leq 0,1$ 


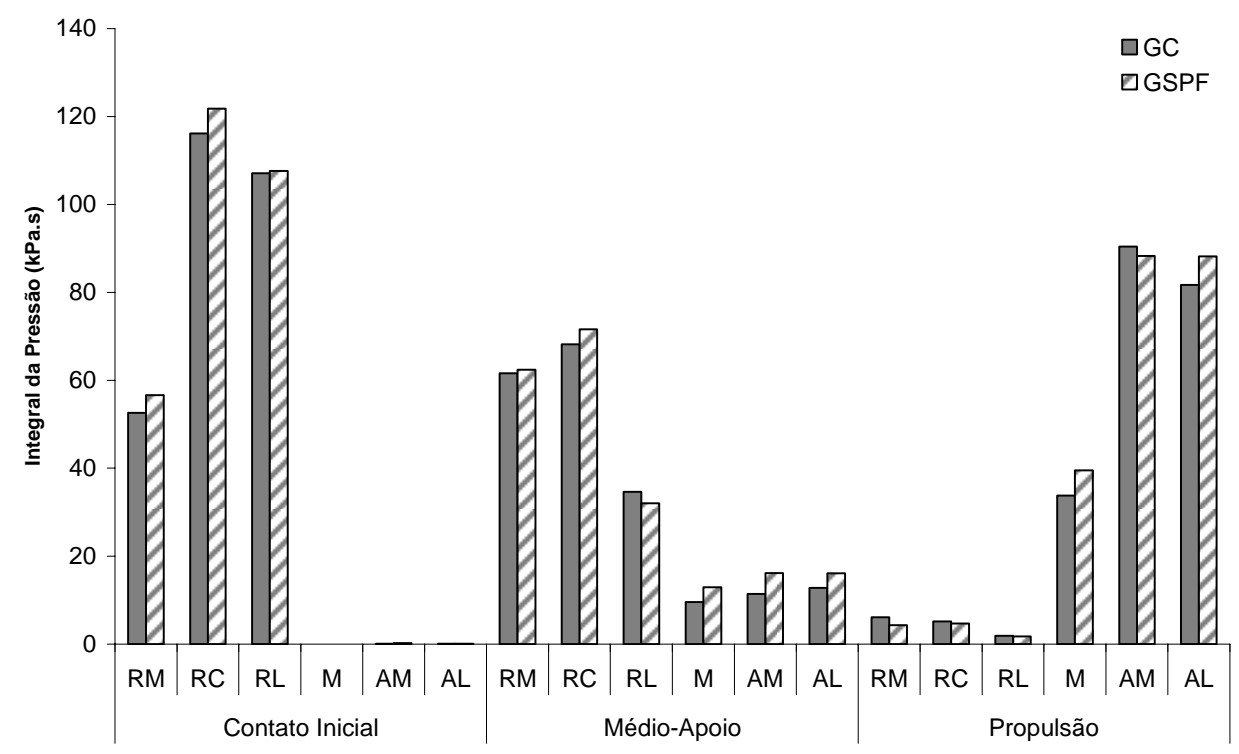

Figura 18. Integral da pressão (kPa.s) nas 6 áreas plantares durante 0 contato Inicial, 0 médio-apoio e a propulsão da fase de apoio da marcha entre os grupos controle (GC) e síndrome da dor patelofemural (GSPF). $\mathrm{RM}=$ retropé medial, $\mathrm{RC}=$ retropé central, $R L=$ retropé lateral, $M=$ médio-pé, $A M=$ antepé medial e $A M=$ antepé lateral.

\subsection{Discussão do Experimento 3}

Este estudo teve como objetivo avaliar a influência da SPF na distribuição da pressão plantar durante o rolamento do pé na fase de apoio da marcha: no contato inicial, médioapoio e na propulsão. Os principais resultados deste estudo mostram que o GSPF apresentou um rolamento do pé ao longo do apoio na marcha alterado. No contato inicial houve um aumento da área de contato no retropé medial e central, durante o médio-apoio houve um aumento da área de contato no antepé medial e lateral e na propulsão uma diminuição do pico de pressão no antepé medial associada a um aumento da área de contato no antepé lateral do GSPF. O GSPF contacta o retropé mais centro/medialmente, ou seja, realiza um primeiro contato do pé com o solo em uma posição mais evertida. Por outro lado, 
realiza uma propulsão mais direcionada à porção lateral do antepé, sugerindo um aumento da supinação nesta fase.

Segundo Perry (2005), Powers et al. (2002), Mc Poil e Cornwall (1996b), Weist et al. (2004), indivíduos assintomáticos, contatam inicialmente o solo com a articulação subtalar em uma posição levemente supinada produzindo maiores picos de pressão no calcanhar lateral. Imediatamente após este primeiro contato, começa a pronação da articulação subtalar onde se observa um aumento da superfície de apoio no calcanhar, excursionando o centro de pressão no sentido medial e anterior. Esta pronação continua e tem seu pico no médio-apoio, por volta de $40 \%$ do tempo de apoio. Em torno de $50 \%$ do tempo de apoio inicia-se a supinação (apoio-médio terminal), e a articulação subtalar permanece supinada durante toda a propulsão.

Na marcha do GSPF, uma entrada do pé mais evertido no contato inicial parece ter diminuído a excursão da pronação inicial que deve ocorrer nesta fase para a absorção da carga. Consequentemente, a pronação teve que acontecer no médio-apoio de forma mais pronunciada, evidenciada pelo aumento da área de contato no antepé medial ocorrendo em seguida uma re-inversão, levando à uma aumento da área de contato no antepé lateral ainda nesta fase e culminando com um desprendimento do pé mais lateral, evidenciado pelo aumento da área de contato no antepé lateral e diminuição do pico de pressão no antepé medial durante a propulsão.

Willems et al (2006) realizaram um estudo prospectivo da distribuição da pressão plantar associada à cinemática do retropé com sujeitos fisicamente ativos (estudantes de Educação Física). Os indivíduos que desenvolveram lesões relacionadas ao exercício mostraram um contato inicial mais central, acompanhado de uma posição mais pronada do retropé no médio-apoio e uma propulsão mais lateralizada durante a corrida. Segundo este 
autor, esta propulsão mais lateralizada - o que faz com que o desprendimento do pé não aconteça pelo hálux - ocorre provavelmente porque durante a fase de médio-apoio, o aumento da pronação leva o pé a ficar menos estável. Então ocorre uma re-inversão nesta fase para prover um braço de alavanca mais rígido durante 0 desprendimento dos pés (Willems et al., 2006) Este padrão se assemelha aos resultados encontrados neste presente estudo na marcha de sujeitos com SPF.

Por outro lado, Thijs et al (2007) avaliaram prospectivamente a distribuição da pressão plantar na marcha de militares que desenvolveram SPF, encontrando um contato inicial lateralmente direcionado para estes indivíduos, sugerindo uma posição menos evertida do calcanhar. No entanto, os militares estudados eram predominantemente do sexo masculino e estavam passando por um intenso período de atividade física, o que limita a generalização destes achados.

O presente estudo contribui para a discussão da influência da SPF no rolamento dos pés durante o apoio da marcha, pois avaliou as três subfases do apoio na marcha em uma amostra composta por indivíduos predominantemente do sexo feminino e semelhante ao grupo controle quanto à prática de atividade física, diminuindo a possibilidade do gênero e da prática de atividade física serem fatores intervenientes nos resultados.

O desprendimento dos pés lateralizado encontrado neste estudo, por outro lado, concorda com (Thijs et al., 2007) que encontraram um desprendimento dos pés mais lateral na marcha de militares que desenvolveram SPF. Estes resultados parecem confirmar uma associação entre uma propulsão mais lateralizada e a SPF.

Vale a pena ressaltar que a distribuição da pressão plantar permitiu interpretações indiretas sobre o comportamento do rolamento do pé, já que não se realizou uma avaliação cinemática neste estudo. No entanto, Willems et al. (2006)demonstraram em um estudo com 
400 indivíduos que existe concordância entre os dados da distribuição da pressão plantar e a cinemática do retropé. Além disto, Dixon e McNally (2008), mostraram que a avaliação da pressão plantar descalça pode ser utilizada como parâmetro dinâmico objetivo para a prescrição e avaliação do efeito de palmilhas antipronação, como uma alternativa aos sistemas de avaliação da cinemática (Willems et al., 2006) (Dixon e McNally, 2008).

Estes achados contribuem para a discussão da literatura sobre parâmetros objetivos para o uso de calçados, órteses e taping que restringem a pronação do complexo tornozelopé na reabilitação da SPF. Futuros estudos que avaliem a pressão plantar antes e depois do uso de restritores da pronação em indivíduos com SPF que apresentem alterações semelhantes às encontradas neste estudo no rolamento do pé durante a marcha, podem contribuir para esta discussão.

\subsection{Considerações finais do Experimento 3}

Os sujeitos com SPF apresentaram um contato inicial medialmente direcionado no retropé e propulsão lateralmente direcionada no antepé quando comparados aos sujeitos assintomáticos. Este padrão cinético observado sugere um rolamento do pé no apoio da marcha inicialmente mais evertido finalizando com uma propulsão mais lateralizada em sujeitos com síndrome da dor patelofemural. 


\section{DISCUSSÃO DOS EXPERIMENTOS 1, 2 E 3}

Os principais resultados do experimento 1 mostraram que não houve associação significativa entre as medidas clínicas estáticas do retropé e joelho e a SPF. Por outro lado, nos experimentos 2 e 3, onde se avaliou a distribuição da pressão plantar durante o descer escadas e a marcha, respectivamente, observaram-se alterações do padrão cinético externo do GSPF.

No experimento 2, durante a fase de apoio do descer escadas, o GSPF mostrou uma diferente geometria de colocação do pé no solo com aumento da área de contato nas regiões mais mediais de retropé e médio-pé, sobrecarregando com menos intensidade o pé ao descer escadas. E no experimento 3, o GSPF confirmou este contato inicial medialmente direcionado no retropé, mas agora em uma tarefa menos desafiadora, e uma propulsão lateralmente direcionada no antepé.

Durante o contato inicial na marcha, o apoio medializado no retropé nos sujeitos com SPF, sugere uma entrada do pé com o calcâneo mais evertido, provavelmente diminuindo a excurssão de pronação que deve ocorrer nesta fase para a absorção do impacto. Portanto, uma pronação mais excessiva provavelmente teve que acontecer na fase de médio-apoio. Devido à estreita relação entre a articulação subtalar e articulação tíbio-társica, esta pronação excessiva levaria a tíbia a uma maior rotação medial. Esta maior rotação medial da tíbia levaria a um aumento da rotação medial do fêmur para manter a relativa rotação lateral da tíbia devido ao movimento de travamento do joelho associado à extensão no médio-apoio . Este aumento da rotação medial do fêmur lateralizaria a patela em relação ao fêmur, aumentando as forças de compressão na articulação patelofemural. Este aumento de 
compressão de forma cíclica e repetitiva poderia estar associado à ocorrência e/ou agravamento da SPF.

Apesar deste estudo não ter avaliado a cinemática do retropé e joelho para afirmar esta sequência de eventos articulares e de não ter feito uma avaliação antes da ocorrência da disfunção, o padrão no contato inicial encontrado nos resultados de pressão plantar para os sujeitos com SPF sugerem a associação entre a pronação em excessiva e a ocorrência da SPF, já citada na literatura (Tibério 1987; Powers, 2003)

Por outro lado, os resultados dinâmicos mostraram uma propulsão mais lateralizada durante a marcha nos sujeitos com SPF o que faz com que o desprendimento do pé não aconteça pelo hálux. Este aumento da re-inversão nesta fase provavelmente acontece para prover um braço de alavanca mais rígido durante o desprendimento dos pés (Willems et al., 2006) e sugere um aumento da movimentação médio-lateral do rolamento do pé, ou seja, um aumento dos movimentos do pé nos planos frontal e transverso. No estudo de Eng e Pierrynosky (1994), o uso de palmilhas anti-pronação em sujeitos com SPF reduziu os movimentos do retropé e joelho no plano transverso na propulsão da marcha. Estes autores discutem que apesar do retropé não estar mais em contato com o solo durante a propulsão, a diminuição da pronação, promovida pela palmilha durante as duas primeiras fases do apoio (contato inicial e médio-apoio), reduziu a quantidade de supinação durante a propulsão. Para esses autores, reduções discretas no valgo do retropé - promovidas pelas palmilhas antipronação - parecem reduzir o movimento na articulação do joelho nos planos transverso e frontal, e, consequentemente, levariam a um sucesso no tratamento clínico da SPF com o uso de palmihas (Eng e Pierrynowski, 1993). Fazendo o raciocínio inverso, uma maior movimentação do retropé e consequentemente do joelho nos planos frontal e transverso, poderia estar associada à ocorrência de SPF. 
Durante o descer escadas, não foram avaliadas as subfases do apoio, portanto não é possível detalhar os resultados de pressão plantar durante o rolamento do pé nesta tarefa. De qualquer forma, os resultados de pressão plantar encontrados no retropé seguem o mesmo padrão dos resultados encontrados na marcha, onde os sujeitos com SPF mostraram um apoio medializado, sugerindo um apoio evertido do retropé no solo. Assim, a possível reação cinemática em cadeia promovida no membro inferior levando a um aumento da compressão patelar, pode também ocorrer nesta habilidade motora.

A partir destes resultados, podemos concluir que os sujeitos com SPF, apesar de não se distinguirem dos sujeitos assintomáticos por meio da avaliação clínica estática, quando foram avaliados dinamicamente houve alterações. Durante o descer escadas, a hipótese inicial de que os sujeitos com SPF apresentariam maiores pressões e contato nas regiões mediais dos pés foi confirmada. No entanto, durante a marcha a hipótese foi confirmada somente durante o apoio inicial, sugerindo que o padrão evertido do retropé no contato inicial influenciou no rolamento do pé de maneira a levar à um aumento da supinação durante a propulsão.

Thijs et al. (2008) não encontraram diferença na postura estática dos pés avaliada por meio do índice de postura do pé entre corredores iniciantes recreacionais que desenvolveram ou não SPF. Este índice é um instrumento validado para avaliar a postura do pé em seis categorias (normal, pronado, muito pronado, supinado e muito supinado) por meio de palpação e observação visual, estando os sujeitos em posição ortostática relaxada e apoio bipodal. Neste estudo, estes autores encontram para a mesma amostra, maiores picos de força vertical no contato inicial e propulsão da corrida nos corredores que desenvolveram SPF em comparação com os corredores que permaneceram assintomáticos. Os resultados 
do presente estudo estão de acordo com os achados do estudo descrito anteriormente, onde a SPF esteve mais relacionada às alterações dinâmicas do que estáticas.

Por outro lado, Levinger e Gilleard (2006) encontraram relação entre 0 alinhamento do retropé na posição ortostática relaxada bipodal e o pico de eversão do calcâneo durante a marcha de indivíduos com SPF, afirmando que esta postura pode ser usada para explicar o padrão do movimento do retropé durante a marcha para os indivíduos com esta disfunção.

O experimento 1 utilizou-se de medidas clínicas que foram avaliadas em decúbito dorsal e posição ortostática em apoio bipodal. Em comparação às tarefas dinâmicas avaliadas nos outros dois experimentos - descer escadas e marcha - a posição em apoio bipodal relaxado é muito menos desafiadora em termos de demanda motora.

Mc Poil e Cornwall (1996b) realizaram um estudo para determinar se 17 medidas estáticas dos membros inferiores em indivíduos assintomáticos - incluindo medidas de amplitude de movimento da subtalar e altura da tuberosidade do navicular na posição ortostática - poderiam ser usadas para predizer a magnitude da movimentação do retropé durante a marcha. Este estudo demonstrou que nenhuma das medidas estáticas foi capaz de predizer a magnitude ou tempo para a pronação máxima na marcha. Por outro lado, estes mesmos autores realizaram um outro estudo para determinar a relação entre as medidas estáticas: ângulo do retropé na posição ortostática bipodal, ângulo do retropé na posição ortostática unipodal e ângulo do retropé com a subtalar em posição neutra com o padrão da movimentação do retropé durante a marcha em sujeitos assintomáticos e encontraram que 0 ângulo do retropé em apoio unipodal pode servir como indicador clínico da pronação máxima que ocorre durante a fase de apoio da marcha (McPoil e Cornwall, 1996a). 
Futuros estudos que avaliem medidas estáticas em posições mais desafiadoras como apoio unipodal, assim como em diferentes ângulos de flexão do joelho podem aprofundar a discussão sobre medidas clínicas estáticas associadas à SPF.

Durante a reabilitação de pacientes com SPF torna-se importante a avaliação dinâmica dos indivíduos que apresentam esta disfunção, com o objetivo de encontrar alterações que podem não ser detectadas por meio da avaliação estática.

A avaliação dinâmica da distribuição da pressão plantar pode contribuir como parâmetro objetivo na prescrição, efeito agudo e acompanhamento do uso de calçados, órteses ou taping anti-pronação, assim como na reabilitação por meio de fortalecimento muscular, reeducação sensória motora e treino de atividades motoras como a marcha e 0 descer escadas em pacientes com SPF que apresentem alterações como a pronação excessiva e/ou prolongada. Além disto, sugere-se que os tratamentos fisioterápicos para a SPF que objetivam o alívio da dor associada à reabilitação funcional nas atividades de vida diária, podem ser avaliados em termos da sobrecarga imposta no pé do membro afetado, sendo um parâmetro objetivo sobre as compensações nas atividades motoras do cotidiano dos pacientes.

Finalmente, estudos que avaliem a cinemática do retropé associada à distribuição da pressão plantar em indivíduos com SPF antes e após intervenções com calçados, órteses ou taping, assim como antes e após tratamentos com exercícios para a SPF podem ampliar a discussão sobre a reabilitação desta disfunção desafiadora para a fisioterapia. 


\section{$9 \quad$ CONCLUSÕES}

Os resultados deste estudo mostram que não houve associação entre a disfunção e 0 alinhamento postural estático do retropé e joelho. No entanto, durante o descer escadas a síndrome da dor patelofemural esteve relacionada à um contato medialmente direcionado no retropé e médio-pé, assim como menores sobrecargas plantares, provavelmente associadas ao aumento significativo da dor relatada pelos sujeitos após a tarefa. Na marcha, os sujeitos com síndrome da dor patelofemural também realizaram um contato inicial medialmente direcionado no retropé e uma propulsão mais lateralizada no antepé, sugerindo uma posição mais evertida do calcanhar no contato inicial e aumento da supinação na propulsão.

A síndrome da dor patelofemural não esteve associada ao alinhamento postural estático do retropé e joelho, mas influenciou o padrão dinâmico da distribuição da pressão plantar tanto na marcha como no descer escadas. Estes achados confirmam a importância da avaliação dinâmica durante a reabilitação dos indivíduos com esta disfunção. 
ABNT. Acessibilidade a edificações, mobiliário, espaços e equipamentos urbanos. Associação Brasileira de Normas Técnicas;2004.Disponível em: http://www.abnt.org.br. Bevilaqua-Grossi D.Contribuições da Fisioterapia para o Estudo da Síndrome da Dor Femoropatelar[Livre-Docência].Ribeirão Preto:Departamento de Biomecânica Medicina e Reabilitação do Aparelho Locomotor,Universidade de São Paulo;2007.

Bizzini M, Childs JD, Piva SR, Delitto A. Systematic review of the quality of randomized controlled trials for patellofemoral pain syndrome. J Orthop Sports Phys Ther. 2003; 33(1):420.

Brechter $\mathrm{JH}$, Powers CM. Patellofemoral joint stress during stair ascent and descent in persons with and without patellofemoral pain. Gait Posture. 2002; 16(2):115-123.

Breslow NE, Day NE. Statistical Methods in Cancer Research _ The Analysis of Case-Control Studies. IARC Scientific Publications;1980.

Breslow NE, Day NE. Statistical Methods in Cancer Research _ The Desing and Analysis of Cohort Studies. IARC Scientific Publications; 1987.

Burnfield JM, Few CD, Mohamed OS, Perry J. The influence of walking speed and footwear on plantar pressures in older adults. Clin Biomech (Bristol, Avon). 2004; 19(1):78-84.

Calmbach WL, Hutchens M. Evaluation of patients presenting with knee pain: Part II. Differential diagnosis. Am Fam Physician. 2003; 68(5):917-922.

Cavanagh P, Ulbrecht J. The foot in diabetes. United Kingdom: Chichester;1994.

Cheung RT, Ng GY, Chen BF. Association of footwear with patellofemoral pain syndrome in runners. Sports Med. 2006; 36(3):199-205. 
DeHaven KE, Lintner DM. Athletic injuries: comparison by age, sport, and gender. Am J Sports Med. 1986; 14(3):218-224.

Dixon SJ, McNally K. Influence of orthotic devices prescribed using pressure data on lower extremity kinematics and pressures beneath the shoe during running. Clin Biomech (Bristol, Avon). 2008; 23(5):593-600.

Earl JE, J H, R DC. Patterns of Dynamic Malalignment, Muscle Ativation, Joint Motion and Patellofemoral-Pain Syndrome. J Sport Rehabil. 2005; 14(215-233.

Emami MJ, Ghahramani MH, Abdinejad F, Namazi H. Q-angle: an invaluable parameter for evaluation of anterior knee pain. Arch Iran Med. 2007; 10(1):24-26.

Eng JJ, Pierrynowski MR. Evaluation of soft foot orthotics in the treatment of patellofemoral pain syndrome. Phys Ther. 1993; 73(2):62-68; discussion 68-70.

Eng JJ, Pierrynowski MR. The effect of soft foot orthotics on three-dimensional lower-limb kinematics during walking and running. Phys Ther. 1994; 74(9):836-844.

France L, Nester C. Effect of errors in the identification of anatomical landmarks on the accuracy of $Q$ angle values. Clin Biomech (Bristol, Avon). 2001; 16(8):710-713.

Fredericson M, Yoon K. Physical examination and patellofemoral pain syndrome. Am J Phys Med Rehabil. 2006; 85(3):234-243.

Grelsamer RP. Patellar nomenclature: the Tower of Babel revisited. Clin Orthop Relat Res. $2005 ; 436): 60-65$.

Gross MT, Foxworth JL. The role of foot orthoses as an intervention for patellofemoral pain. $J$ Orthop Sports Phys Ther. 2003; 33(11):661-670.

Heintjes E, Berger MY, Bierma- Zeinstra SMA, Bersnsen RMD, Verhaar JAN, Koes BW. (2005). "Exercise therapy for Patellofemoral pain syndrome (Cochrane Review)."

Herrington $\mathrm{L}$. The difference in a clinical measure of patella lateral position between 
individuals with patellofemoral pain and matched controls. J Orthop Sports Phys Ther. 2008; 38(2):59-62.

Herrington LC. The inter-tester reliability of a clinical measurement used to determine the medial-lateral orientation of the patella. Man Ther. 2002; 7(3):163-167.

Ireland ML, Willson JD, Ballantyne BT, Davis IM. Hip strength in females with and without patellofemoral pain. J Orthop Sports Phys Ther. 2003; 33(11):671-676.

lunes DH, Castro FA, Salgado HS, Moura I, Oliveira AS, Bevilaqua-Grossi D. Confiabilidade intra e interexaminadores e Repetibilidade da Avaliação Postural pela Fotogrametria. Rev Bras Fisioter. 2005; 9(3):327-334.

Johnston LB, Gross MT. Effects of foot orthoses on quality of life for individuals with patellofemoral pain syndrome. J Orthop Sports Phys Ther. 2004; 34(8):440-448.

Juhn MS. Patellofemoral pain syndrome: a review and guidelines for treatment. Am Fam Physician. 1999; 60(7):2012-2022.

Katchburian MV, Bull AM, Shih YF, Heatley FW, Amis AA. Measurement of patellar tracking: assessment and analysis of the literature. Clin Orthop Relat Res. 2003; 412):241-259.

Kernozek TW, Zimmer KA. Reliability and running speed effects of in-shoe loading measurements during slow treadmill running. Foot Ankle Int. 2000; 21(9):749-752.

La Botz M. Patellofemoral Syndrome. Physician and Sportsmedice. 2004; 32(7):22-29.

LaBella C. Patellofemoral pain syndrome: evaluation and treatment. Prim Care. 2004; 31(4):977-1003.

Levinger P, Gilleard W. An evaluation of the Rearfoot Posture in individuals with Patellofemoral Pain Syndrome. Journal of Sports Science and Medicine. 2004; 3):8-14. Levinger $\mathrm{P}$, Gilleard $\mathrm{W}$. The heel strike transient during walking in subjects with patellofemoral pain syndrome. Phys Ther in Sport. 2005; 6(83-88. 
Levinger P, Gilleard W. Relationship between static posture and rearfoot motion during walking in patellofemoral pain syndrome: effect of a reference posture for gait analysis. J Am Podiatr Med Assoc. 2006; 96(4):323-329.

Levinger P, Gilleard W. Tibia and rearfoot motion and ground reaction forces in subjects with patellofemoral pain syndrome during walking. Gait Posture. 2007; 25(1):2-8.

Livingston LA. The quadriceps angle: a review of the literature. J Orthop Sports Phys Ther. 1998; 28(2):105-109.

Livingston LA, Mandigo JL. Bilateral rearfoot asymmetry and anterior knee pain syndrome. J Orthop Sports Phys Ther. 2003; 33(1):48-55.

Lysholm J, Gillquist J. Evaluation of knee ligament surgery results with special emphasis on use of a scoring scale. Am J Sports Med. 1982; 10(3):150-154.

Mascal CL, Landel R, Powers C. Management of patellofemoral pain targeting hip, pelvis, and trunk muscle function: 2 case reports. J Orthop Sports Phys Ther. 2003; 33(11):647-660.

McConnell J. Management of patellofemoral problems. Manual Theraphy. 1996; 1(60-66.

McPoil TG, Cornwall MW. Relationship between three static angles of the rearfoot and the pattern of rearfoot motion during walking. J Orthop Sports Phys Ther. 1996a; 23(6):370-375.

McPoil TG, Cornwall MW. The relationship between static lower extremity measurements and rearfoot motion during walking. J Orthop Sports Phys Ther. 1996b; 24(5):309-314.

Melo de Paula G, Molinero de Paula VR, Almeida GJM, Machado VEI, Baraúna MA, Bevilaqua-Grossi D. Correlação entre a dor anterior do joelho e a medida do ângulo "Q" por intermédio da fotometria computadorizada. Rev.bras.fisioter. 2004; 8(1):39-43.

Messier SP, Davis SE, Curl WW, Lowery RB, Pack RJ. Etiologic factors associated with patellofemoral pain in runners. Med Sci Sports Exerc. 1991; 23(9):1008-1015.

Mittlmeier T, Weiler A, Sohn T, Kleinhans L, Mollbach S, Duda G, et al. novel Award Second 
Prize Paper. Functional monitoring during rehabilitation following anterior cruciate ligament reconstruction. Clin Biomech (Bristol, Avon). 1999; 14(8):576-584.

Nakagawa TH, Muniz TB, Baldon RB, Serrão FV. A abordagem funcional dos músculos do quadril no tratamento da síndrome da dor femoro-patelar. Fisioter. Mov. 2008; 21(1):65-72.

Natri $A$, Kannus $P$, Jarvinen $M$. Which factors predict the long-term outcome in chronic patellofemoral pain syndrome? A 7-yr prospective follow-up study. Med Sci Sports Exerc. 1998; 30(11):1572-1577.

Neumann DA. Kinesiologie of Musculoskeletal System: Foundation for Physical Rehabilitation. Missoury: Mosby;2002.

Nissen CW, Cullen MC, Hewett TE, Noyes FR. Physical and arthroscopic examination techniques of the patellofemoral joint. J Orthop Sports Phys Ther. 1998; 28(5):277-285.

Orlin MN, McPoil TG. Plantar pressure assessment. Phys Ther. 2000; 80(4):399-409.

Perry J. Análise de Marcha. Barueri: Manole;2005.

Powers CM. The influence of altered lower-extremity kinematics on patellofemoral joint dysfunction: a theoretical perspective. J Orthop Sports Phys Ther. 2003; 33(11):639-646.

Powers CM, Chen PY, Reischl SF, Perry J. Comparison of foot pronation and lower extremity rotation in persons with and without patellofemoral pain. Foot Ankle Int. 2002; 23(7):634-640.

Powers CM, Heino JG, Rao S, Perry P. The influence of patellofemoral pain on lower limb loading during gait. Clinical Biomechanics. 1999; 14(10):722-728.

Powers CM, Maffucci R, Hampton S. Rearfoot posture in subjects with patellofemoral pain. J Orthop Sports Phys Ther. 1995; 22(4):155-160.

Powers CM, Mortenson S, Nishimoto D, Simon D. Criterion-related validity of a clinical measurement to determine the medial/lateral component of patellar orientation. J Orthop Sports Phys Ther. 1999; 29(7):372-377. 
Robinson RL, Nee RJ. Analysis of hip strength in females seeking physical therapy treatment for unilateral patellofemoral pain syndrome. J Orthop Sports Phys Ther. 2007; 37(5):232-238. Sacco I, Aliberti S, Queiroz B, Pripas D, Kieling I, Kimura A, et al. Reliability of photogrammetry in relation to goniometry for postural lower limb assessment. Rev. bras. fisioter. 2007; 11(5):411-417.

Sacco IC, Amadio AC. A study of biomechanical parameters in gait analysis and sensitive cronaxie of diabetic neuropathic patients. Clin Biomech (Bristol, Avon). 2000; 15(3):196-202.

Salsich GB, Perman WH. Patellofemoral joint contact area is influenced by tibiofemoral rotation alignment in individuals who have patellofemoral pain. J Orthop Sports Phys Ther. $2007 ; 37(9): 521-528$.

SAPO - Software para avaliação postural. Disponível em : http://sapo.incubadora.fapesp.br/portal

Saxena A, Haddad J. The effect of foot orthoses on patellofemoral pain syndrome. J Am Podiatr Med Assoc. 2003; 93(4):264-271.

Shephard RJ. Limits to the measurement of habitual physical activity by questionnaires. $\mathrm{Br} \mathrm{J}$ Sports Med. 2003; 37(3):197-206; discussion 206.

Tauton JE, Ryan MB, Clement DB, McKenzie, Lloyd- Smith DR, Zumbo BD. A retrospective case-control analysis of 2002 running injuries. British Journal of Sports Medicine. 2002; ;36(2):95.

Teyhen D, Molloy J, Yeykal N, Tragord B, Neal M, ES N. Influence of running shoe type on distribution and magnitude of plantar pressures among those with pes planus or pes cavus feet .Proceedings of the Emed Scientific Meeting, Munich ,Ger, June 2006.

Thijs Y, De Clercq D, Roosen P, Witvrouw E. Gait-related intrinsic risk factors for patellofemoral pain in novice recreational runners. Br J Sports Med. 2008; 42(6):466-471. 
Thijs Y, Van Tiggelen D, Roosen P, De Clercq D, Witvrouw E. A prospective study on gaitrelated intrinsic risk factors for patellofemoral pain. Clin J Sport Med. 2007; 17(6):437-445.

Thomee R, Renstrom P, Karlsson J, Grimby G. Patellofemoral pain syndrome in young women. I. A clinical analysis of alignment, pain parameters, common symptoms and functional activity level. Scand J Med Sci Sports. 1995; 5(4):237-244.

Tibério D. The effect of excessive subtalar joint pronation on patellofemoral mechanics:a theoretical model. J Orthop Sports Phys Ther. 1987; 9(160-165.

Weist $R$, Eils $E$, Rosenbaum D. The influence of muscle fatigue on electromyogram and plantar pressure patterns as an explanation for the incidence of metatarsal stress fractures. Am J Sports Med. 2004; 32(8):1893-1898.

Willems TM, De Clercq D, Delbaere K, Vanderstraeten G, De Cock A, Witvrouw E. A prospective study of gait related risk factors for exercise-related lower leg pain. Gait Posture. 2006; 23(1):91-98.

Williamson A, Hoggart B. Pain: a review of three commonly used pain rating scales. J Clin Nurs. 2005; 14(7):798-804.

Wilson T. The measurement of patellar alignment in patellofemoral pain syndrome: are we confusing assumptions with evidence? J Orthop Sports Phys Ther. 2007; 37(6):330-341.

Winter D. Biomechanics and motor control of human gait. Ontario: University of Watterloo Press;1991.

Woodland LH, Francis RS. Parameters and comparisons of the quadriceps angle of collegeaged men and women in the supine and standing positions. Am J Sports Med. 1992; 20(2):208-211. 


\title{
ANEXO 1 - Termo de Consentimento Livre e Esclarecido
}

\section{Estudo biomecânico do comportamento dinâmico do tornozelo e pé em sujeitos com síndrome} fêmoro-patelar: marcha e descer escadas.

\author{
Aluna: Sandra Aliberti \\ Orientadora: Profa. Dra. Isabel de C. N. Sacco
}

Este estudo tem como objetivo central avaliar os movimentos da articulação do tornozelo e do pé em pacientes com dor no joelho. Para isso, o (a) senhor(a) será avaliado(a) através de alguns testes que estão descritos mais detalhadamente abaixo. Estes testes serão aplicados no Laboratório de Biomecânica do Movimento e da Postura Humana da FMUSP e terão duração de aproximadamente 1 hora.

- Estágio 1: o(a) senhor(a) será entrevistado por meio de um questionário sobre seus dados pessoais, sua história geral, e doenças já existentes. Um segundo questionário será aplicado para obtermos as condições atuais de seu joelho no dia a dia.

- Estágio 2: serão avaliadas medidas clínicas do alinhamento do joelho e tornozelo do(a) senhor(a) por meio de marcadores adesivos em pontos do joelho e tornozelo e fotografia.

- Estágio 3: (a) senhor(a) colocará palmilhas eletrônicas e uma meia antiderrapante, e o senhor (a) andará no seu ritmo em uma pista de 10 metros e posteriormente descerá uma escada de quatro degraus algumas vezes. Um computador gravará todos os dados enquanto o senhor (a) se locomover.

0 experimento é composto de procedimentos não-invasivos e não envolve qualquer risco à sua saúde física e mental, além dos riscos encontrados nas atividades normais do cotidiano, por isso não haverá indenização no caso de qualquer intercorrência. Porém, no caso de qualquer intercorrência acontecer durante 0 experimento, este será interrompido e o encaminharemos para o Hospital Universitário para receber toda a assistência necessária.Os resultados desta pesquisa, guardadas as devidas identificações e mantida a confidencialidade, serão analisados e utilizados única e exclusivamente para fins científicos

$\mathrm{O} \mathrm{Sr} \mathrm{(a)} \mathrm{tem} \mathrm{a} \mathrm{liberdade} \mathrm{de} \mathrm{desistir} \mathrm{de} \mathrm{sua} \mathrm{participação} \mathrm{nesta} \mathrm{pesquisa} \mathrm{a} \mathrm{qualquer} \mathrm{momento} \mathrm{sem} \mathrm{prejuízo} \mathrm{à}$ continuidade da assistência no HU. Caso necessite entrar em contato com os pesquisadores responsáveis por esta pesquisa o $\mathrm{sr}$ (a) deve entrar em contato com as docentes responsáveis pela Pesquisa: Profa. Dra. Isabel de Camargo Neves Sacco - Tel. 3092.7464. Estaremos a sua disposição.

Identificação do CEP-HU: Endereço: Av. Prof. Lineu Prestes, 2565 - Cidade Universitária - CEP: 05508-900 São Paulo - SP - Telefones: 3039-9457 ou 3039-9479 - E-mail: cep@hu.usp.br.

Após o conhecimento dos testes aos quais estarei me submetendo, concordo em participar deste projeto de pesquisa, na condição de voluntário permitindo a realização destes testes, conforme condições descritas acima.

Assinatura do voluntário:

Assinatura do pesquisador:

Data

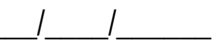




\section{ANEXO 2 -Aprovação da CAPPesq}

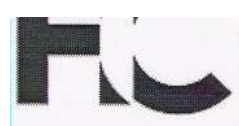

IOSPITAL DAS BLHIPHS

A FACULDADE DE MEBSCHOA

\section{APROVAÇÃO}

A Comissão de Ética para Análise de Projetos de Pesquisa - CAPPesq da Diretoria Clínica do Hospital das Clínicas e da Faculdade de Medicina da Universidade de São Paulo, em sessão de 23.02.06, APROVOU o Protocolo de Pesquisa $n^{\circ} 1237 / 05$, intitulado: "Estudo biomecânico do comportamento dinâmico do tornozelo e pé em sujeitos com síndrome fêmoro-patelar: marcha e descer escadas." apresentado pelo Departamento de FISIOTERAPIA, FONOAUDIOLOGIA

E TERAPIA OCUPACIONAL, inclusive o Termo de Consentimento Livre e Esclarecido.

Cabe ao pesquisador elaborar e apresentar à CAPPesq, os relatórios parciais e final sobre a pesquisa (Resolução do Conselho Nacional de Saúde n 196, de 10.10.1996, inciso IX. 2, letra "c")

Pesquisador(a) Responsável: Profa. Dra Isabel Camargo Neves Sacco Pesquisador(a) Executante: Sra Sandra Aliberti

CAPPesq, 23 de Fevereiro de 2006.

PROF. DR. EUCLIDES AYRES DE CASTILHO Presidente da Comissão de Ética para Análise de Projetos de Pesquisa

\footnotetext{
Comissão de Ética para Análise de Projetos de Pesquisa do HCFMUSP e da FMUSP

Diretoria Clínica do Hospital das Clínicas da Faculdade de Medicina da Universidade de São Paulo Rua Ovídio Pires de Campos. 225, $5^{\circ}$ andar - CEP 05430010 - São Paulo - SP 


\section{ANEXO 3 - Escala Funcional do Joelho de Lysholm}

Assinalar a alternativa que melhor descreve o paciente:

\section{Apresenta claudicação?}

( )Nenhuma

( )Leve ou periódica

( )Acentuada e constante

\section{Como é o suporte?}

( )Apoio total

( )Bengala ou muleta

( )Sustentação de peso impossível

3. Qual o grau de dificuldade para subir escadas?

( )Sem problemas

( )Levemente prejudicado

( )Um degrau de cada vez

( )Incapaz

4. Qual o grau de dificuldade para agachar?

( )Sem problemas

( )Levemente prejudicado

( ) Não acima de $90^{\circ}$

( )Incapaz

Considerando as atividades de andar, correr e saltar, responda as questões de 5 a 7 :

5. Qual o grau de instabilidade?
( ) Nunca tem falseio
( )Raramente durante esporte ou outro esforço vigoroso
( )Freqüentemente durante esporte ou outro esporte vigoroso
( )Ocasionalmente em atividades diárias
( )Muitas vezes em atividades diárias
( )Todos os passos

6. Sente dor?
( ) Nenhuma
( ) Inconstante e leve durante esforço intenso
( ) Acentuada ao ter falseio
( )Acentuada durante esforço intenso
( ) Acentuada durante ou depois de andar mais de $2 \mathrm{Km}$
( )Acentuada durante ou depois de andar menos de $2 \mathrm{Km}$
( )Constante e intensa

\section{Apresenta edema?}
( )Nenhum
( )Ao ter falseio
( )Com esforço intenso
( )Com esforço comum
( )Constante

8. Apresenta atrofia da coxa?
( ) Nenhuma
( ) $1-2 \mathrm{~cm}$
( )Mais de $2 \mathrm{~cm}$

\author{
Total: 5 pontos \\ 5 pontos \\ 3 pontos \\ 0
}

Total: 5 pontos

5 pontos

3 pontos

Total: 10 pontos

10 pontos

6 pontos

2 pontos

0

Total: 5 pontos

5 pontos

4 pontos

2 pontos

0

Total: 70 pontos
30 pontos

25 pontos

20 pontos

10 pontos

5 pontos

0

30 pontos

25 pontos

20 pontos

15 pontos

10 pontos

5 pontos

0

10 pontos

7 pontos

5 pontos

2 pontos

0

Total: 5 pontos 5 pontos

3 pontos

0

Pontuação total: 


\title{
ANEXO 4 - Resumo XI EMED Scientific Meeting Dundee, Escócia, 2008 \\ LOADS IMPOSED TO THE PAINFUL LEG VERSUS THE PAIN FREE LEG DURING STAIR DESCENT IN PATELLOFEMORAL PAIN SYNDROME
}

\author{
Sandra. Aliberti, Mariana. S.C. Costa, Isabel C.N. Sacco
}

Laboratory of Biomechanics of Human Movement and Posture Dept. of Physiotherapy, Speech and Occupational Therapy at School of Medicine, University of São Paulo,Brazil.

\section{NTRODUCTION}

Patellofemoral Pain Syndrome (PFPS) is one of the most common injuries of the knee ${ }^{1}$. Nevertheless, the rationales basis for its rehabilitation remains unclear ${ }^{2}$. Investigating the loading patterns in the symptomatic and asymptomatic leg during a demanding task that is usually related to an increasing of symptoms may provide guides in the compensatory strategies adopted by the subjects with PFPS. The aim of this study was to compare plantar pressure distribution during the stance phase of stair descent between painful and pain free leg in subjects with unilateral PFPS

\section{PATIENTS AND METHODS}

17 volunteers(10 women, 34 feet) with diagnose of unilateral PFPS (30 17 years old, $65 \pm 13 \mathrm{~kg}, 167 \pm 10 \mathrm{~cm}$ ) served as subjects for this study. $47,1 \%$ had the left side affected and $52,9 \%$ had the right one. Plantar pressure distribution during the stairs descending condition (stair with five steps constructed using Brazilian Association of Technical Rules standardization) was measured using Pedar X System at $100 \mathrm{~Hz}$. Contact area, peak pressure and pressure-time integral were calculated in 6 areas: medial,central and lateral rearfoot, midfoot, medial and lateral forefoot. Plantar Pressure data were compared between sides using ANOVA three-way for repeated measures followed by Neuman-Keuls test.

\section{RESULTS AND DISCUSSION}

Both sides produced the same contact area $(p>0,05)$. As shown on table 1, the painful leg presented lower peak pressures at medial forefoot and lower pressure time integrals at medial and lateral forefoot when compared to the pain free leg.

Pressures under the forefoot during the descending stairs condition reach about $80 \%$ of body weight as this is the first region of the foot to make contact with the steps 3 .

Table1. Means $( \pm S D)$ of the foot regions statistically different in peak pressure and pressure-time integral between painful and pain free.

\begin{tabular}{ccccc}
\hline Variables & $\begin{array}{c}\text { Foot } \\
\text { Region }\end{array}$ & $\begin{array}{c}\text { Painful } \\
\text { leg }\end{array}$ & $\begin{array}{c}\text { Painfree } \\
\text { leg }\end{array}$ & $\mathbf{p}$ \\
\hline PP & $\begin{array}{c}\text { Medial } \\
\text { Forefoot }\end{array}$ & $316.8 \pm 68.2$ & $374.8 \pm 108.5$ & .031 \\
\hline PP & $\begin{array}{c}\text { Lateral } \\
\text { Forefoot }\end{array}$ & $245.5 \pm 62.4$ & $278.1 \pm 64.2$ & .000 \\
\hline PTI & $\begin{array}{c}\text { Medial } \\
\text { Forefoot }\end{array}$ & $139.7 \pm 34.7$ & $157.3 \pm 36.2$ & .039 \\
\hline PTI & $\begin{array}{c}\text { Lateral } \\
\text { Forefoot }\end{array}$ & $109.0 \pm 35.1$ & $128.1 \pm 37.7$ & .025 \\
\hline
\end{tabular}

Finding lower peak pressures at the forefoot in the painful leg suggests that these subjects tend to diminish the loads imposed to the painful leg at the weight acceptance, when the knee is under an eccentric flexion with a great demand of quadriceps muscle. It is in agreement with a study that found a reduced knee extensor moment during downstairs condition in subjects with PFPS 4 . Besides that, lower pressure-time integrals in the forefoot, 
confirms that the subjects with PFPS spend less time loading the painful leg probably to avoid increasing symptoms.

\section{SUMMARY}

Subjects with unilateral PFPS decrease the loads imposed to the painful leg compared to the pain free leg at the forefoot, which is the first region to make contact to the ground during stairs descending task.

\section{REFERENCES}

1. Clement D B et al. .Phys Sports Med 9:47-58, 1981

2.La Botz M. Physician and Sportsmedice32 : 22-29, 2004

3.Lundeen S et all, Foot \& Ankle Int 15:324-328, 1994.

4.Brechter,J H et all, Gait Posture 16 :115-23, 2002

\section{ACKNOWLEDGEMENTS}

Thanks to FAPESP (2005/03803-0) for the financial support. 
ANEXO 5 - Resumo XI EMED Scientific Meeting Dundee, Escócia, 2008

\title{
RELATIONSHIP BETWEEN PLANTAR PRESSURE AND PATELLOFEMORAL PAIN SYNDROME DURING GAIT
}

\author{
Sandra Aliberti, Mariana. S.C. Costa, Isabel C.N. Sacco
}

Laboratory of Biomechanics of Human Movement and Posture - Physical Therapy, Speech and Occupational Therapy dept. - School of Medicine of the University of São Paulo, Brazil.

\section{NTRODUCTION}

Our hypothesis is that Patellofemoral Pain Syndrome (PFPS) may be related to a greater contact area and pressures at the medial portions of the feet, based on the fact that this dysfunction can be linked to an excessive pronation of the rearfoot ${ }^{1}$ as well as an excessive medial rotation of the hip ${ }^{2}$. These kinematic alterations may lead consequently to an increase in plantar pressures over medial regions during gait. The purpose of this study was to investigate the relationship of plantar pressure distribution with PFPS at the stance phase of gait.

\section{METHODS}

74 volunteers served as subjects for this study: 30 (26 women) with PFPS diagnosis (PFPS) (30 $\pm 7 y$, $63 \pm 12 \mathrm{~kg}, 165 \pm 9 \mathrm{~cm})$ and $44(39$ women) asymptomatic subjects (CG) $(30 \pm 8 \mathrm{yr}, 60 \pm 11 \mathrm{~kg}, 165 \pm 9 \mathrm{~cm})$. Plantar pressure distribution during gait (10 meters walkway, cadence between 100 and $112 \mathrm{bpm}$ ) was measured using Pedar X System at $100 \mathrm{~Hz}$. Both legs (88 feets) in control group and the painful leg (30 feets) in PFPS group were analyzed. Contact area, peak pressure and pressure-time integral were evaluated in 6 plantar regions: medial (MR), central (CR) and lateral (LR) rearfoot, midfoot (M), medial (MF) and lateral (LF) forefoot. Groups and plantar areas were compared using 3 ANOVAs two-way (2X6) followed by Newman-Keuls post hoc test $(\alpha=.05)$.

\section{RESULTS AND DISCUSSION}

Both groups were equal for pressure - time integral $(p>0.05)$. Statistical tests did not confirm effect of areas or groups for pressure-time integrals. Therefore, ANOVA detected an effect of the group independent of plantar areas for peak pressure $(p=0.040)$ : PFPS subjects presented lower peak pressures $(240.6 \pm 34.6 \mathrm{kPa})$ compared to CG $(255.7 \pm 34.2 \mathrm{kPa})$. This suggests that these subjects decrease loads imposed to the feet probably to avoid increasing the symptoms and is in accordance to Powers et $\mathrm{al}^{3}$ study that found lower ground reaction forces in subjects with this syndrome during gait.

Table1. Means $( \pm S D)$ of Contact Area $\left(\mathrm{cm}^{2}\right)$ in 6 areas of the PFPS group and CG (control group).

\begin{tabular}{lccc}
\hline Areas & PFPS & CG & p \\
\hline MR & $12.2 \pm 3.5$ & $10.5 \pm 3.5$ & $.048^{*}$ \\
\hline CR & $17.1 \pm 1.9$ & $16.62 \pm 2.1$ & .565 \\
\hline LR & $5.80 \pm 3.6$ & $6.49 \pm 3.2$ & .404 \\
\hline M & $18.96 \pm 3.4$ & $16.44 \pm 6.1$ & $.013^{*}$ \\
\hline MF & $34.14 \pm 3.1$ & $34.52 \pm 4.1$ & .649 \\
\hline LF & $24.46 \pm 2.2$ & $22.80 \pm 3.6$ & $.046^{*}$
\end{tabular}

$\S$ Newman-Keuls p-values. *Represent significant differences.

There was also an effect of area and groups in contact area ( $p=.018)$. PFPS subjects showed significantly larger contact areas in the medial rearfoot, midfoot and lateral forefoot as shown in table 1 . These results suggest that subjects with PFPS have a greater medial excursion of the foot at the initial stance (at heel strike) and a lateral excursion in late stance. A recent study ${ }^{4}$ confirmed a roll over process of the foot more on the lateral side in PFPS subjects during gait, which is in line with our findings at the forefoot. On the other hand, these authors observed a heel strike in a less pronated position in individuals with PFPS, while our findings suggest that a greater medial excursion of the rearfoot can be related to this syndrome.

Our findings confirm our initial hypothesis that this dysfunction may be related to an increase in contact area at medial portions of the feet at the initial contact during gait. 


\section{SUMMARY}

PFPS is related to a greater medial excursion at rearfoot and greater lateral excursion at forefoot during gait. Besides that, these subjects decrease loads imposed to the feet possibly to reduce symptoms.

\section{REFERENCES}

1. Levinger $P$ et al. Phys Ther in Sport. 6: 83-88, 2005

2. Mascal, C. L. J Orthop Sports Phys Ther .33: 647-60, 2003

3. Powers C M et al. Clin Biomech 14:722-8, 1999

4. Thijs Y.et al Clin J Sport Med. 17: 437-45, 2007

\section{ACKNOWLEDGEMENTS}

Thanks to FAPESP (2005/03803-0) for the financial support. 